\title{
Marine-Derived Macrocyclic Alkaloids (MDMAs): Chemical and Biological Diversity
}

\author{
Hanan I. Althagbi ${ }^{1,2}$, Walied M. Alarif ${ }^{3, *}$, Khalid O. Al-Footy ${ }^{2}$ and Ahmed Abdel-Lateff ${ }^{4,5}$ \\ 1 Department of Chemistry, Faculty of Science, University of Jeddah, P.O. Box 13151, \\ Jeddah 21493, Saudi Arabia; halthagbi@uj.edu.sa \\ 2 Department of Chemistry, Faculty of Science, King Abdulaziz University, P.O. Box 80203, \\ Jeddah 21589, Saudi Arabia; kalfooti@kau.edu.sa \\ 3 Department of Marine Chemistry, Faculty of Marine Sciences, King Abdulaziz University, P.O. Box 80207, \\ Jeddah 21589, Saudi Arabia \\ 4 Department of Natural Products and Alternative Medicine, Faculty of Pharmacy, King Abdulaziz University, \\ P.O. Box 80260, Jeddah 21589, Saudi Arabia; aabdellatteff@kau.edu.sa \\ 5 Department of Pharmacognosy, Faculty of Pharmacy, Minia University, Minia 61519, Egypt \\ * Correspondence: walied1737@yahoo.com; Tel.: +966-5603-520-34
}

Received: 14 May 2020; Accepted: 15 July 2020; Published: 17 July 2020

check for updates

\begin{abstract}
The curiosity and attention that researchers have devoted to alkaloids are due to their bioactivities, structural diversity, and intriguing chemistry. Marine-derived macrocyclic alkaloids (MDMAs) are considered to be a potential source of drugs. Trabectedin, a tetrahydroisoquinoline derivative, has been approved for the treatment of metastatic soft tissue sarcoma and ovarian cancers. MDMAs displayed potent activities that enabled them to be used as anticancer, anti-invasion, antimalarial, antiplasmodial, and antimicrobial. This review presents the reported chemical structures, biological activities, and structure-activity relationships of macrocyclic alkaloids from marine organisms that have been published since their discovery until May 2020. This includes 204 compounds that are categorized under eight subclasses: pyrroles, quinolines, bis-quinolizidines, bis-1-oxaquinolizidines, 3-alkylpiperidines, manzamines, 3-alkyl pyridinium salts, and motuporamines.
\end{abstract}

Keywords: marine natural products; macrocyclic alkaloids; potential drugs; biological activity

\section{Introduction}

The marine environment is one of the harshest atmospheres on the earth due to its diverse ranges of light, temperature, pressure, and nutrient circumstances [1]. These conditions enable marine organisms to produce extremely different and unprecedented metabolites with a wide range of bioactivities [2,3]. The organisms that live in this environment have immense genetic and biochemical diversity that, being the source of unexplored bioactive products, could be beneficial for the development of potential drugs [4].

The discovery of such drugs is expensive, time-consuming, and risky because it is achieved through complicated processes. Moreover, drug discovery is supported by the combination of databases with dereplication methodologies, such as computer-assisted structure elucidation (CASE) and mass spectrometry or nuclear magnetic resonance (NMR) spectroscopy (metabolite- guided and genome-guided approaches) [3].

Twenty marine-derived compounds have been considered in different clinical trial phases, ranging from Phase I to III. Moreover, four macrocyclic compounds out of eight approved marine-derived drugs have been approved by the Food and Drug Administration (FDA), Australia's Therapeutic Goods Administration, the European Medicines Agency (EMA), and the Japanese Ministry of Health [5]. 
Marine macrocyclic natural products (MMNPs) include four main subclasses according to their structural differences, namely, cyclic depsipeptides, diterpenes, macrolides, and macrocyclic alkaloids. MMNPs have been reported from different sources, including sponges, algae, fungi, mollusks, cyanobacteria, and gorgonians [6].

The unprecedented skeletons of MMNPs and structural complexity have an important role in the potency of their bioactivities. This has enhanced the discovery of anticancer drugs such as trabectedin [7], which is a tetrahydroisoquinoline alkaloidal derivative that has been approved by the FDA and the European Agency for the Evaluation of Medicinal Products (EMEA) as an anticancer drug. Ingenamine $\mathrm{G}$ has been shown to exhibit potent cytotoxic effects against HCT-8 (colon), B16 (leukemia), and MCF-7 (breast) cancer cell lines, as well as antibacterial effects against Staphylococcus aureus, Escherichia coli, four oxacillin-resistant S. aureus strains, and Mycobacterium tuberculosis H37Rv [8]. The potent blocking activity of xestospongin $\mathrm{A}$, araguspongine $\mathrm{B}$, demethylxestospongin $\mathrm{B}$, and araguspongines $\mathrm{C}$ and D on IP3-mediated $\mathrm{Ca}^{2+}$ release from the endoplasmic reticulum vesicles of the rabbit cerebellum has been published [9]. Finally, the antimalarial activity of manzamines has been reported [10].

This review discusses the reported chemical structures, biological effects, and structure-activity relationships (SARs) of eight subclasses of marine-derived macrocyclic alkaloids-pyrroles, quinolines, bis-quinolizidines, bis-1-oxaquinolizidines, 3-alkylpiperidines, manzamines, 3-alkyl pyridinium salts, and motuporamines. Also included within this review are 204 compounds that have been reported since their discovery until May 2020 (Figure 1 and Table 1).

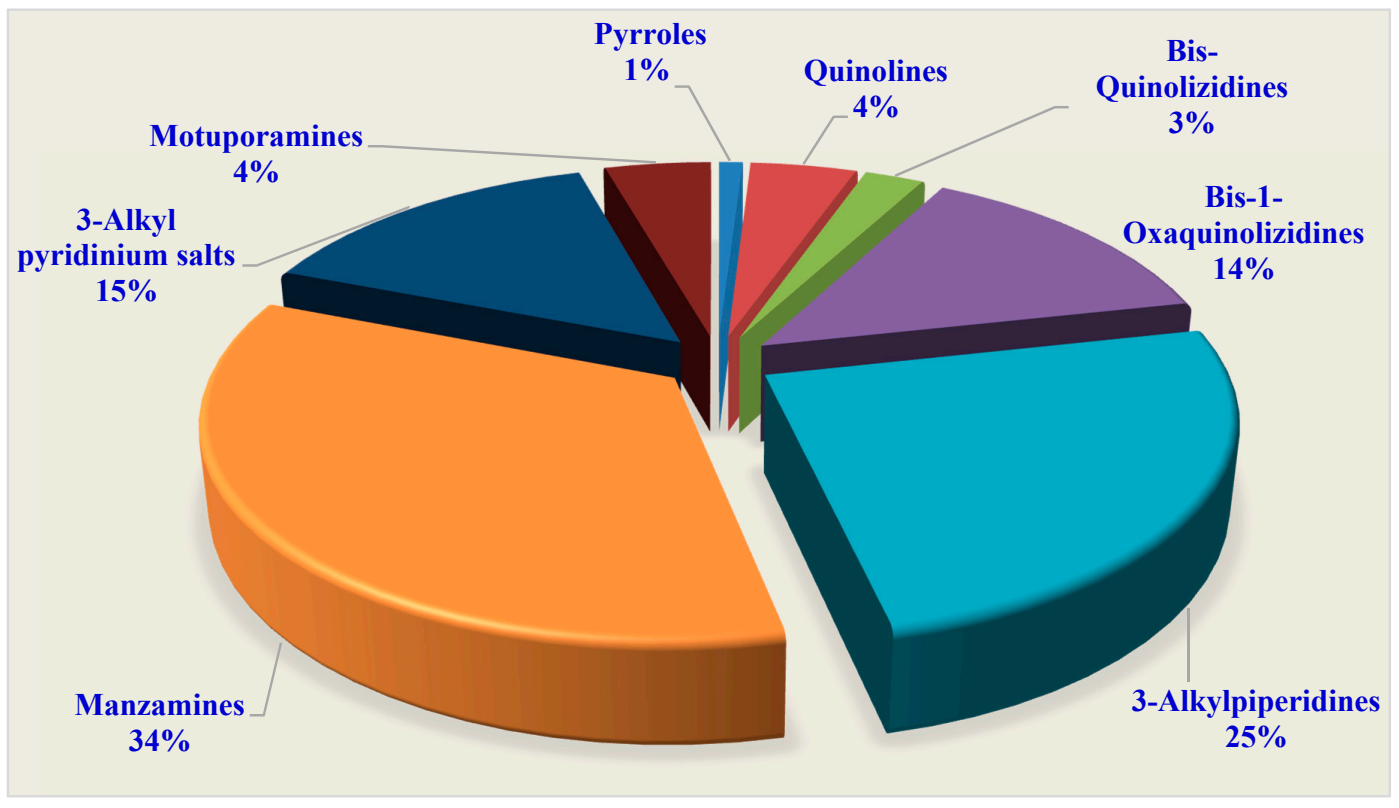

Figure 1. Percentage of marine-derived macrocyclic alkaloids' subclasses. 
Table 1. List of marine-derived macrocyclic alkaloids.

\begin{tabular}{|c|c|c|c|c|}
\hline Compound No. & Subclasses & Name of Compounds & Marine Organism & Biological Activities \\
\hline $1-2$ & Pyrroles & Densanins A and B & Haliclona densaspicula & Anti-inflammatory \\
\hline $3-8$ & \multirow{3}{*}{ Quinolines } & Njaoamines A-F & Reniera sp. & \multirow{16}{*}{$\begin{array}{l}\text { Cytotoxic and } \\
\text { Anti-HIV }\end{array}$} \\
\hline 9-10 & & Njaoamines G-H & Neopetrosia sp. & \\
\hline 11 & & Njaoamine I & Reniera sp. & \\
\hline 12 & \multirow{21}{*}{ Bis-Quinolizidines } & Petrosin & \multirow{2}{*}{ Petrosia seriata } & \\
\hline 13-14 & & Petrosins $A$ and $B$ & & \\
\hline 15 & & Aragupetrosine A & Xestospongia sp. & \\
\hline 16 & & Xestosin A & \multirow{4}{*}{ Xestospongia exigua } & \\
\hline 17 & & Xestospongin A (Araguspongine D) & & \\
\hline 18 & & Xestospongin B & & \\
\hline 19 & & Xestospongin C (Araguspongine E) & & \\
\hline 20 & & Xestospongin D (Araguspongine A) & Xestospongia sp. & \\
\hline $21-26$ & & Xestospongins E-J & Oceanapia sp. & \\
\hline 27 & & (+)-7S-Hydroxyxestospongin A & Xestospongia sp. & \\
\hline 28 & & Demethylxestospongin B & & \\
\hline 29 & & $3 \beta, 3^{\prime} \beta$-Dimethylxestospongin $C$ & Xestospongia sp. & \\
\hline 30 & & 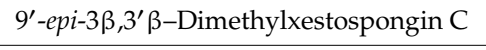 & Neopetrosia exigua & \\
\hline 31 & & Araguspongine B & & \multirow{8}{*}{$\begin{array}{l}\text { Antimicrobial and } \\
\text { Cytotoxic }\end{array}$} \\
\hline 32 & & Araguspongine $\mathrm{C}$ & Xestospongia muta & \\
\hline $33-36$ & & Araguspongines $\mathrm{F}-\mathrm{H}$ and $\mathrm{J}$ & Xestospongia sp. & \\
\hline 37 & & 3a-Araguspongin $C$ & Haliclona exigua & \\
\hline 38-39 & & Araguspongines $\mathrm{K}$ and $\mathrm{L}$ & \multirow[t]{2}{*}{ Neopetrosia exigua } & \\
\hline 40 & & Araguspongine $\mathrm{M}$ & & \\
\hline $41-43$ & & Araguspongines N-P & \multirow{2}{*}{ Xestospongia muta } & \\
\hline 44 & & meso-araguspongine $\mathrm{C}$ & & \\
\hline
\end{tabular}


Table 1. Cont

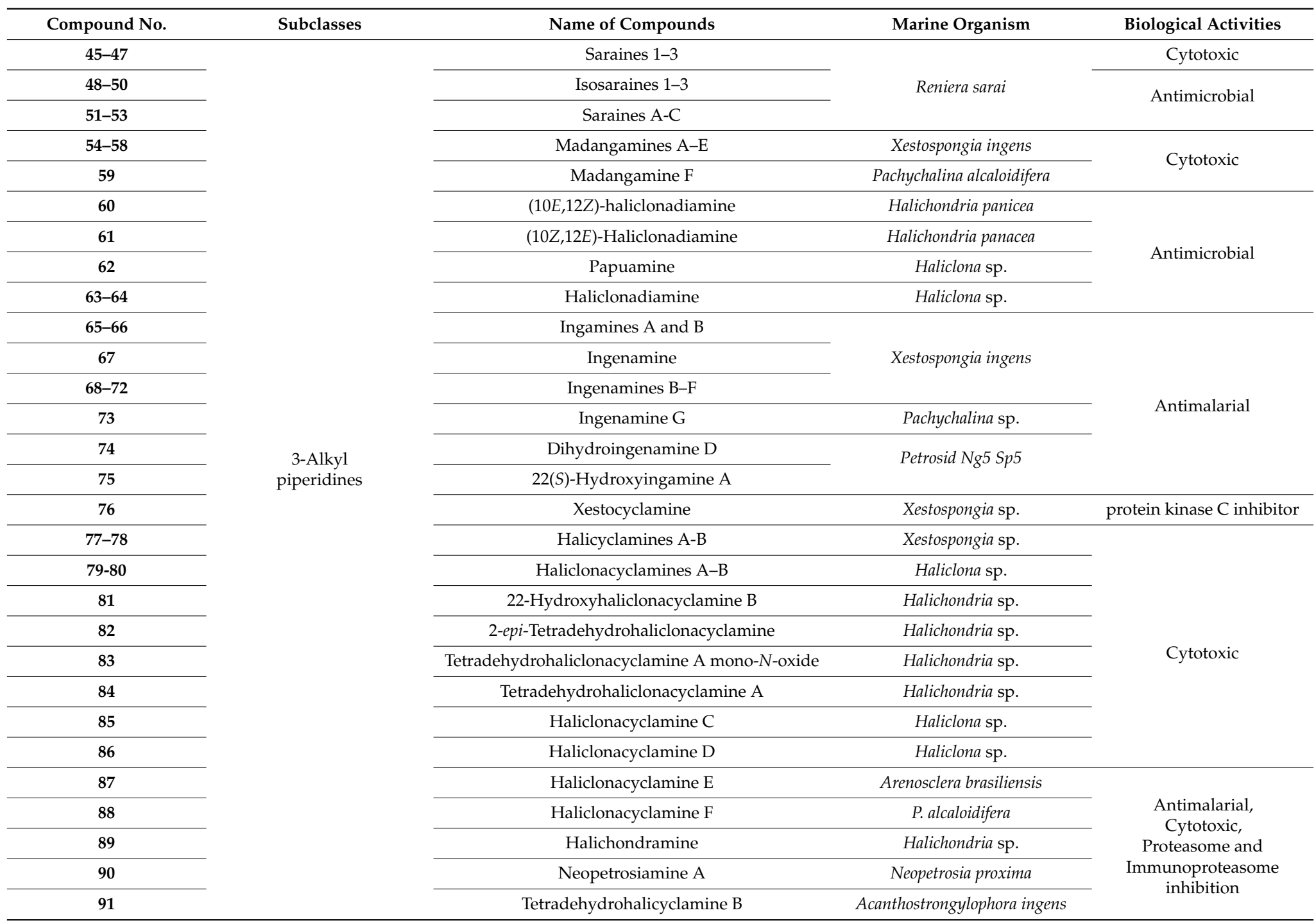


Table 1. Cont

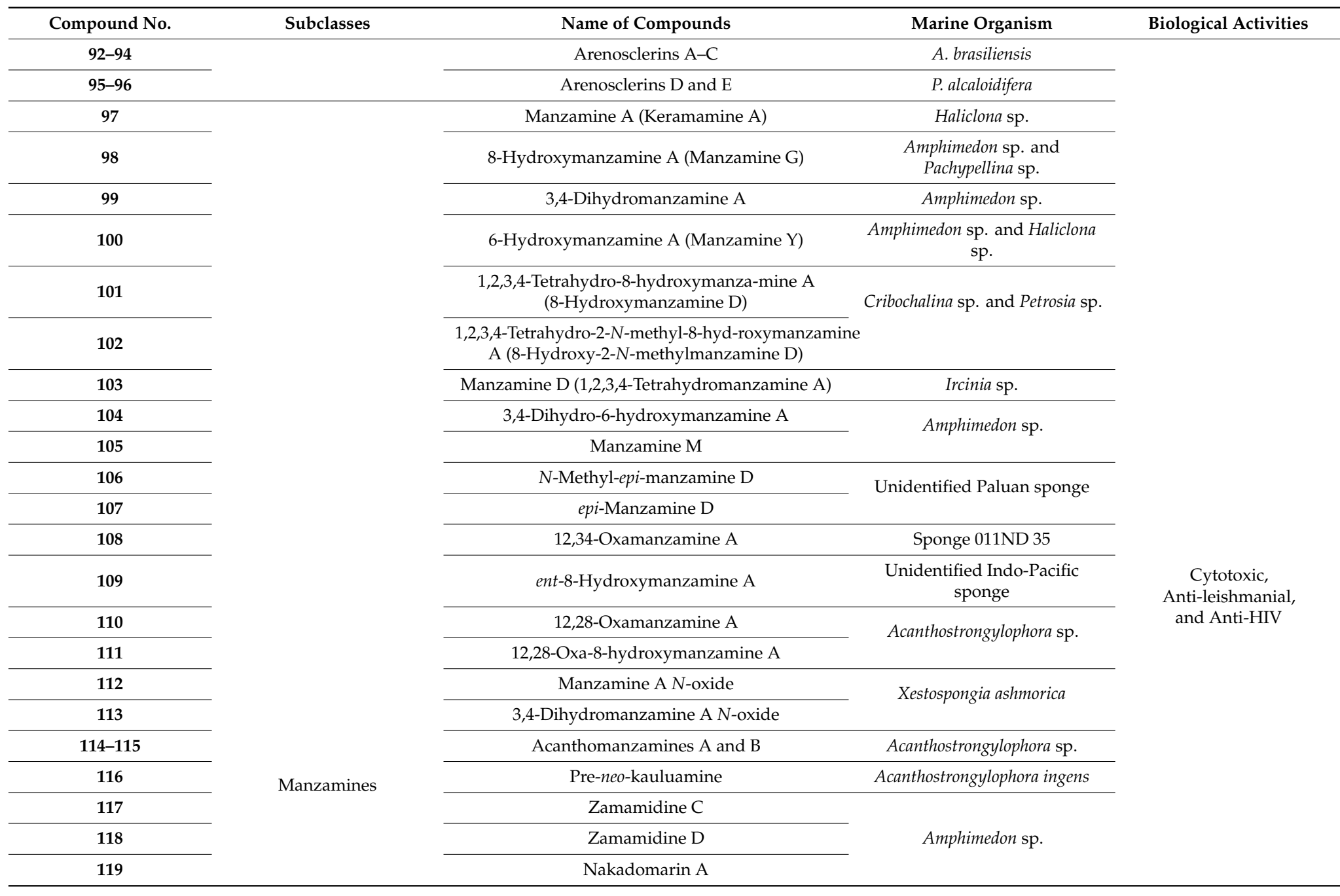


Table 1. Cont

\begin{tabular}{|c|c|c|c|c|}
\hline Compound No. & Subclasses & Name of Compounds & Marine Organism & Biological Activities \\
\hline 120 & & Ircinol A & & \\
\hline 121 & & Ircinal A & Ircinia sp. & \\
\hline 122 & & Ircinal E & & \\
\hline 123 & & 12,28-Oxaircinal A & & \\
\hline 124 & & Manzamine E & \multirow{2}{*}{ Xestospongia sp. } & \\
\hline 125 & & Manzamine F (Keramamine B) & & \\
\hline 126 & & ent-Manzamine $\mathrm{F}$ & & \\
\hline $127-128$ & & ent-12,34-Oxamanzamines $\mathrm{E}$ and $\mathrm{F}$ & Sponge 011ND 35 & \\
\hline 129 & & 12,34-Oxamanzamine E & \multirow{5}{*}{ Acanthostrongylophora sp. } & \\
\hline 130 & & 6-Hydroxymanzamine E & & \\
\hline 131 & & 12,28-Oxamanzamine E & & \\
\hline 132 & & 12,34-Oxa-6-hydroxymanzamine E & & \\
\hline 133 & & 31-Keto-12,34-oxa-32,33-dihydroircinal A & & \\
\hline 134 & & Manzamine B & Haliclona sp. & \\
\hline $135-136$ & & Manzamines $\mathrm{H}, \mathrm{J}$ & Ircinia sp. & \\
\hline 137 & & Manzamine J $N$-oxide & Xestospongiaashmorica & \\
\hline 138 & & 8-Hydroxymanzamine B & Acanthostrongylophora sp. & \\
\hline 139 & & Manzamine L & Amphimedon sp. & \\
\hline 140 & & Manzamine B $N$-oxide & \multirow{3}{*}{ Acanthostrongylophora sp. } & \\
\hline 141 & & 3,4-Dihydromanzamine B N-oxide & & \\
\hline 142 & & 11-Hydroxymanzamine J & & \\
\hline 143 & & Ma'eganedin A & Amphimedon sp. & \\
\hline 144 & & 8-Hydroxymanzamine J & Acanthostrongylophora & \\
\hline 145 & & 3,4-Dihydromanzamine J & Amphimedon sp. & \\
\hline 146-147 & & Acanthomanzamines D and $\mathrm{E}$ & Acanthostrongylophora sp. & \\
\hline 148-149 & & Zamamidines $\mathrm{A}$ and $\mathrm{B}$ & Amphimedon sp. & \\
\hline 150 & & Ircinal B & Ircinia sp. & \\
\hline 151 & & Ircinol B & Amphimedon sp. & \\
\hline
\end{tabular}


Table 1. Cont

\begin{tabular}{|c|c|c|c|c|}
\hline Compound No. & Subclasses & Name of Compounds & Marine Organism & Biological Activities \\
\hline 152 & & Manzamine C & Haliclona sp. & \multirow{14}{*}{ Cytotoxic } \\
\hline 153 & & Keramamine C & Amphimedon sp. & \\
\hline 154 & & Acanthomanzamine C & \multirow{3}{*}{ Acanthostrongylophora sp. } & \\
\hline 155 & & Kepulauamine A & & \\
\hline 156 & & Acantholactam & & \\
\hline 157 & & Acantholactone & Acanthostrongylophora sp. & \\
\hline 158 & & 32,33-Dihydro-31-hydroxymanzamine A & \multirow{3}{*}{ Indonesian sponge } & \\
\hline 159 & & 32,33-Dihydro-6-hydroxymanzamine A-35-one & & \\
\hline 160 & & 32,33-Dihydro-6,31-dihydroxymanzamine A & & \\
\hline 161 & & Manzamine $X$ & Xestospongia sp. & \\
\hline 162 & & 6-Deoxymanzamine $X$ & X. ashmorica & \\
\hline $163-164$ & & Manadomanzamines A and B & Acanthostrongylophora sp. & \\
\hline 165 & & Keramaphidin B & Amphimedon sp. & \\
\hline 166 & & Kauluamine & Prianos sp. & \\
\hline $167-172$ & \multirow{8}{*}{$\begin{array}{c}\text { 3-Alkyl } \\
\text { pyridinium salts }\end{array}$} & Cyclostellettamines A-F & Stelletta maxima & \multirow{6}{*}{$\begin{array}{l}\text { Antimicrobial and } \\
\text { Cytotoxic }\end{array}$} \\
\hline 173-177 & & Cyclostellettamines G-I, K, and L & Pachychalina sp. & \\
\hline 178-179 & & Dehydrocyclostellettamines D, E & Xestospongia sp. & \\
\hline 180 & & 8,8'-Dienecyclostellettamine & Amphimedon compressa & \\
\hline 181-184 & & Cyclostellettamines $\mathrm{N}, \mathrm{R}, \mathrm{O}, \mathrm{Q}$ & Haliclona sp. & \\
\hline 185-192 & & Cyclostellettamines & Haliclona sp. & \\
\hline 193 & & Cyclostellettamine $\mathrm{P}$ & Xestospongia exigua & \\
\hline 194-196 & & Njaoaminiums A-C & Reniera sp. & Cytotoxic \\
\hline 197-205 & Motuporamines & Motuporamines A-I & Xestospongia exigua & Anti-invasion \\
\hline
\end{tabular}




\section{Macrocyclic Alkaloids}

\subsection{Macrocycles Containing a Pyrrole Moiety}

Densanins

Densanins A (1) and B (2) were isolated from the sponge Haliclona densaspicula [11]. Densanins are fused hexacyclic diamine alkaloids with a pyrrole ring that fused to the tricyclic core (Figure 2). Compounds 1 and $\mathbf{2}$ displayed potent inhibitory effects against lipopolysaccharide-induced nitric oxide production in BV2 microglial cells, with $\mathrm{IC}_{50}$ values of 1.05 and $2.14 \mu \mathrm{M}$, respectively [11]. These cells are macrophages of the central nervous system (CNS) and are considered to be a primary form of the active immune defense in the CNS, particularly in Alzheimer's and Parkinson's diseases. Microglia are chronically activated and promote the release of cytokines, which further disrupt normal CNS activities. Thus, the inhibitory effect of inflammatory mediator production in these cells can mitigate the effects of inflammation. Therefore, both metabolites could have potential for development of drugs for treatment of neurodegenerative diseases such as Alzheimer's and Parkinson's diseases [12].
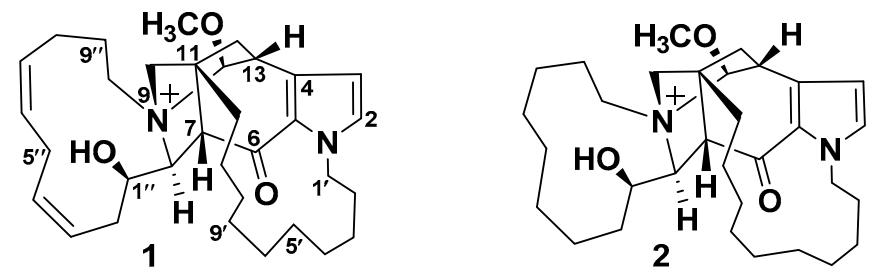

Figure 2. Structures 1 and 2.

\subsection{Macrocycles Containing a Quinoline Moiety}

Njaoamines

Njaoamines are a group of biologically active alkaloids containing a tricyclic nitrogenated nucleus with two hydrocarbon bridges, one of which embeds an 8-hydroxyquinoline moiety. Njaoamines A-F (3-8) (Figure 3) were isolated from the Haplosclerida sponge Reniera sp. [13], whereas njaoamines G (9) and $\mathrm{H}(\mathbf{1 0})$ were isolated from the marine sponge Neopetrosia sp. [14] and njaoamine I (11) from the Haliclona (Reniera) sp. (Figure 3) [15]. Njaoamines showed cytotoxic effects against NSLC A-549 (lung), HT-29 (colon), and MDA-MB-231 (breast) human tumor cell lines. Compounds 3-8 and $\mathbf{1 1}$ showed cytotoxic effects, with $\mathrm{GI}_{50}$ values ranging from 1.5 to $7.2 \mu \mathrm{M}$ against NSLC A-549, from 1.4 to $6.7 \mu \mathrm{M}$ against HT-29, and from 1.5 to $7.2 \mu \mathrm{M}$ against MDA-MB-23 [13,15]. Compounds 9 and 10 exhibited potent toxicity toward brine shrimp, with $\mathrm{LD}_{50}$ values of 0.17 and $0.08 \mu \mathrm{g} / \mathrm{mL}$, respectively [14]. Compound 11 displayed neither an inhibitory effect on human recombinant topoisomerase 1 nor inhibition of the interaction between programmed cell death protein 1(PD-1) and its natural ligand, programmed death-ligand 1(PD-L1), even at the highest concentration tested, $100 \mu \mathrm{M}$ [15].

\subsection{Macrocycles Containing a Bis-Quinolizidine Moiety}

\section{Petrosins}

Petrosin (12), the first reported bis-quinolizidine scaffold linked through a C-16 ring from Petrosia seriata [16]. Later on, two ichthyotoxic bis-quinolizidine alkaloids, petrosins A (13) and B (14), were isolated from the same sponge [17]. In 1988, the structure of petrosin A (13) was revised through 2D-NMR studies by Braekman et al. [18]. Aragupetrosine A (15), along with 12 and 13, was reported from an Okinawan marine sponge, Xestospongia sp. [19] (Figure 4). Compound 15 consists of the $3 \beta$-methyl-trans-2-oxaquinolizidine and 3' $\alpha$-methyl-trans-1-oxoquinolizidine moieties joined by two alkyl chains, which can be viewed as one half moiety of petrosin (12) and the 3 $\alpha$-methyl-trans-1-oxoquinolizidine group [19]. 


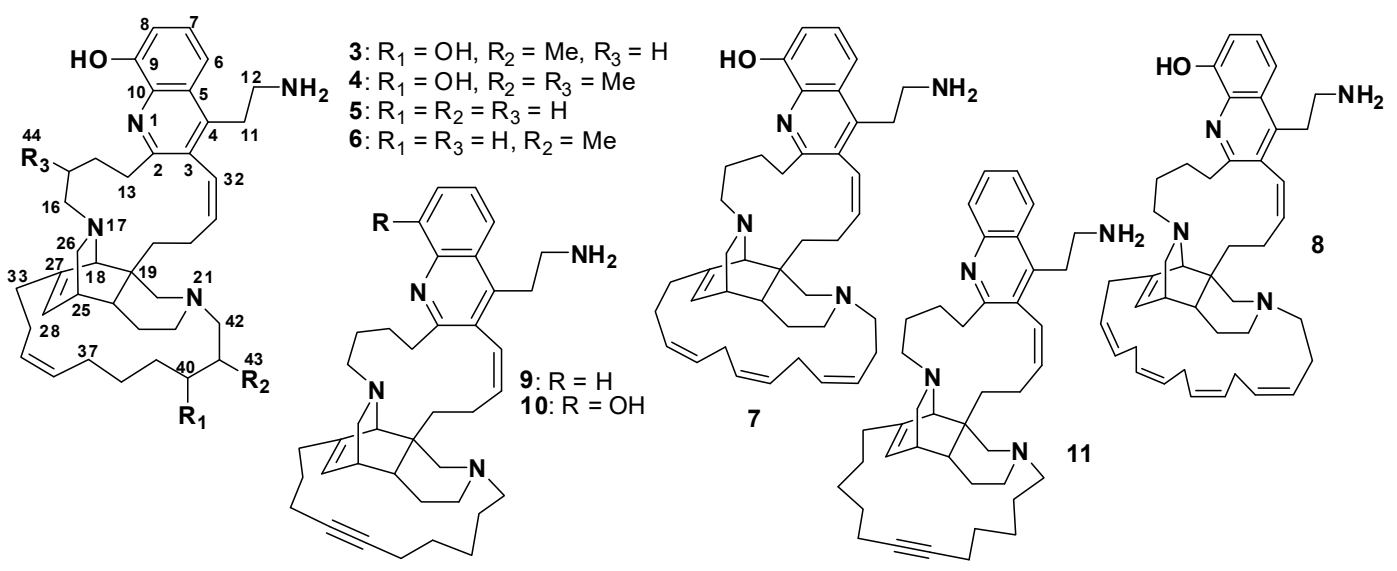

Figure 3. Structures of 3-11.

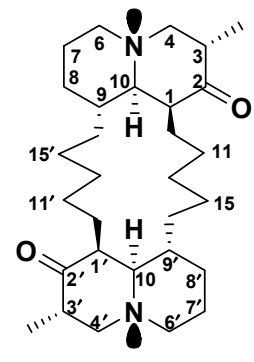

12

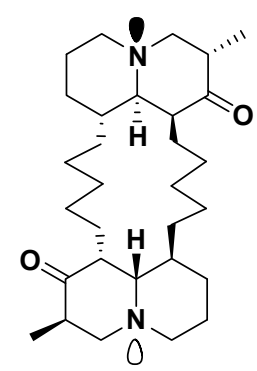

13

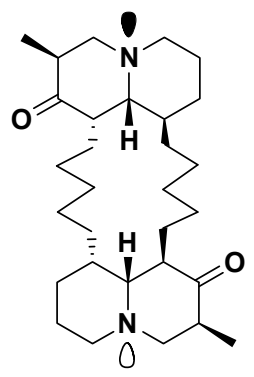

14

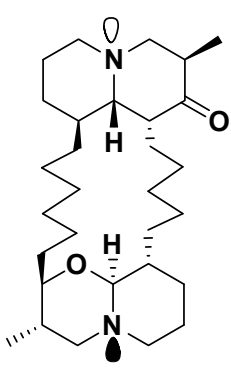

15

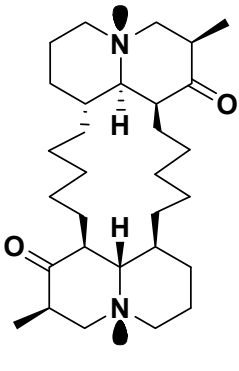

16

Figure 4. Structures of 12-16.

Compounds 12 and 13, isolated from Xestospongia muta, did not show growth inhibition against LU-1 (lung), HepG-2 (liver), HL-60 (leukemia), MCF-7 (breast), and SK-Mel-2 (melanoma) human cancer cells [20]. However, compounds 12, 13, and 15 exhibited vasodilative activity, and 12 and 13 were two-fold more active than papaverine [19]. In addition to ichthyotoxic and vasodilative activities, 12 and 13, isolated from the sponge $P$. similis, showed significant in vitro antiviral activity against human immunodeficiency virus (HIV-1), with $\mathrm{IC}_{50}$ values of 41.3 and $52.9 \mu \mathrm{M}$, respectively [21]. Moreover, 12 and 13 inhibited the early replication of HIV-1 as indicated by multinuclear activation of a galactosidase indicator (MAGI) assay, with giant cell formation and inhibition of human immunodeficiency virus-1 reverse transcriptase (RT) at 10.6 and $14.8 \mu \mathrm{M}$ [21], respectively. Interestingly, 12 did not only show higher activity against HIV than 13 but is also more stable than 13 [21]. Xestosin A (16), another bis-quinolizidine-containing macrocycle, was isolated from the Papua New Guinean sponge Xestospongia exigua [22].

\subsection{Macrocycles Containing a Bis-1-Oxaquinolizidine Moiety}

Xestospongins/Araguspongines

Araguspongines (xestospongins) are a class of macrocyclic alkaloids consisting of a 20-membered ring and two 1-oxaquinolizidine moieties. Xestospongins A (araguspongine D) (17), B (18), C (araguspongine E) (19), and D (araguspongine A) (20) were isolated from the Australian sponge Xestospongia exigua and from Xestospongia sp. [17,23], whereas xestospongins E-J (21-26) (Figure 5) were isolated from the sponge Oceanapia sp. [24]. Compounds 17-20 were found to have an in vivo vasodilator activity [17]. In addition to this activity, 19 and 20 exhibited moderate antimicrobial activity against Aspergillus fumigatus, Aspergillus niger, Rhodotorula, Candida albicans, and Cryptococcus neoformans and moderate to strong antibacterial activity toward Staphyloccus aureus and Escherichia coli [24]. 

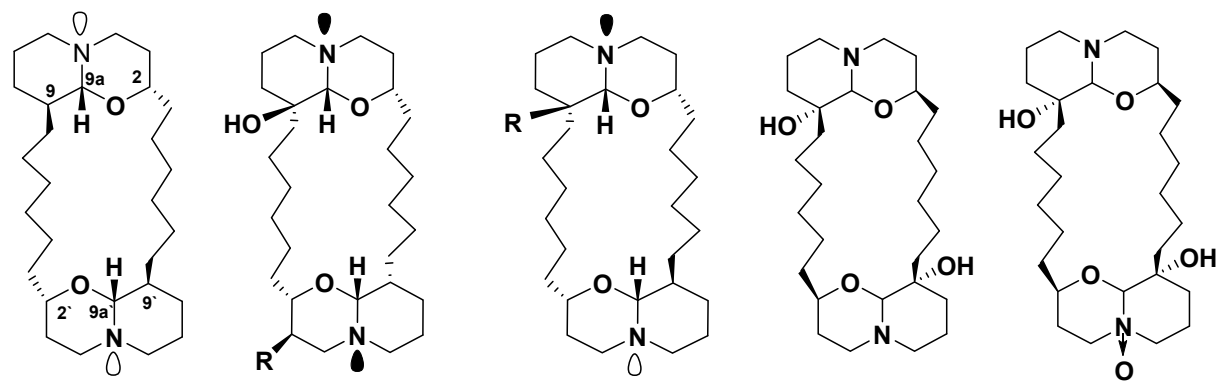

$$
17
$$

18: $R=M e$
28: $R=H$

19: $\mathrm{R}=\mathrm{H}$

20: $\mathrm{R}=\mathrm{OH}$

21

22
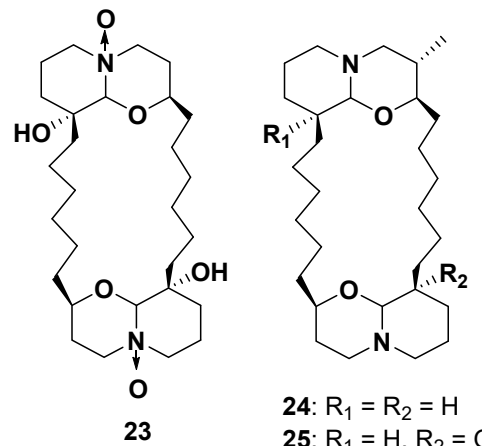

24: $R_{1}=R_{2}=H$

25: $\mathrm{R}_{1}=\mathrm{H}, \mathrm{R}_{2}=\mathrm{OH}$
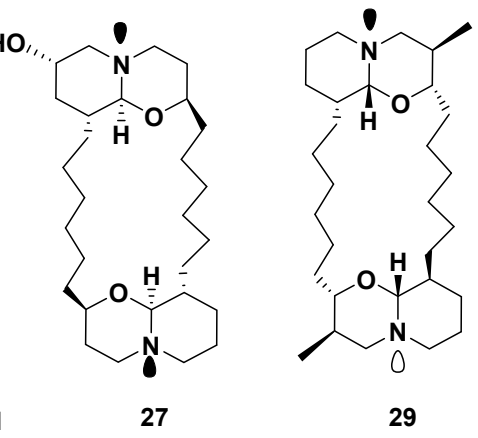

29
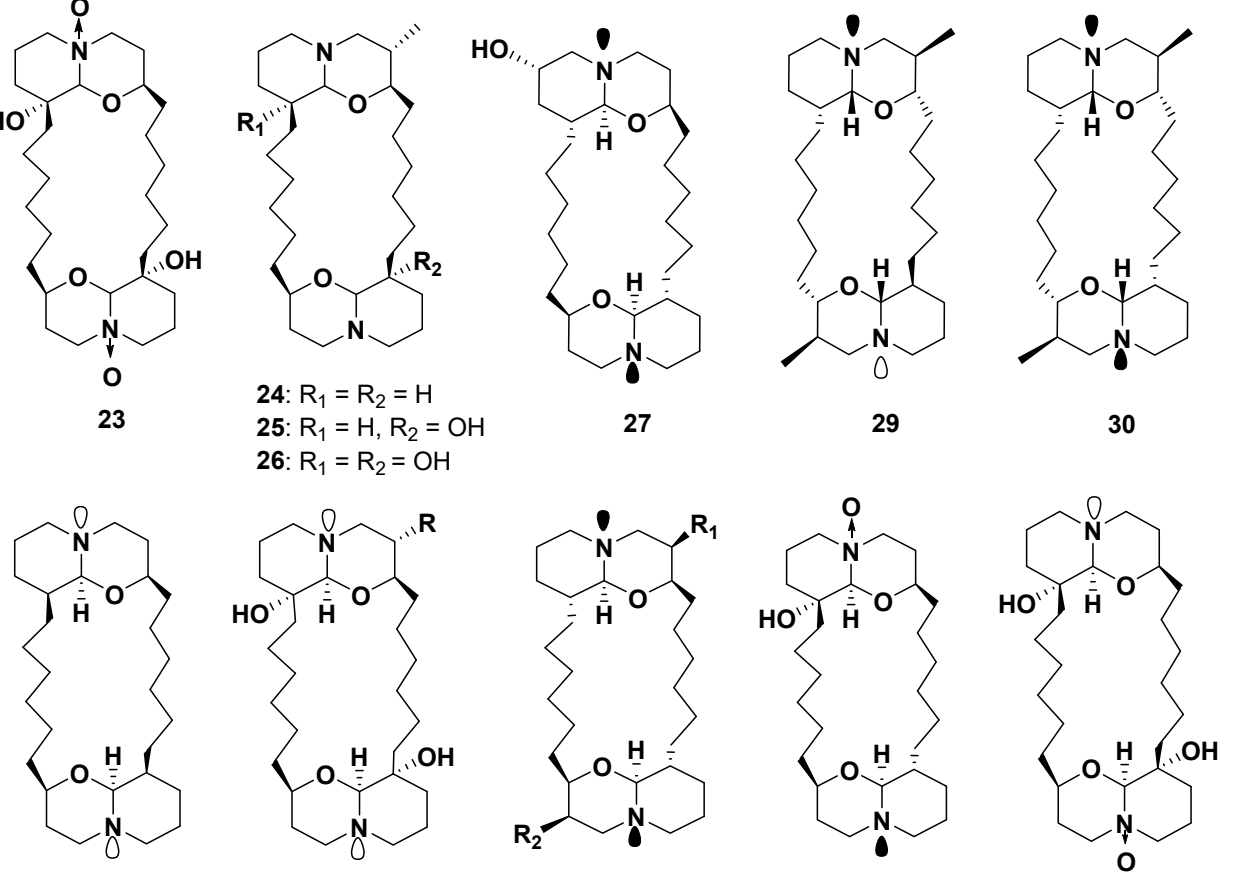

31

$$
\begin{aligned}
& \text { 32: } R=H \\
& \text { 37: } R=M e
\end{aligned}
$$

33: $R_{1}=\alpha-M e, R_{2}=H$

34: $R_{1}=\beta-M e, R_{2}=H$

38

39

35: $R_{1}=\beta-M e, R_{2}=\alpha-M e$

36: $R_{1}=\beta-M e, R_{2}=\beta-M e$

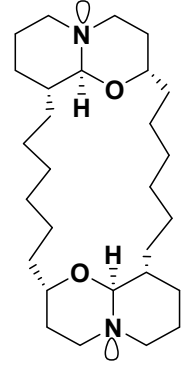

40

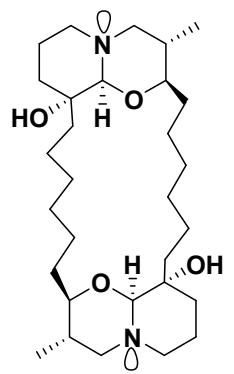

41

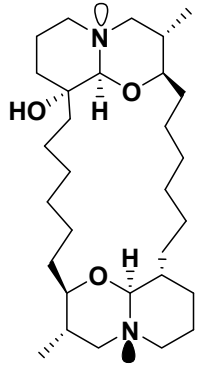

42

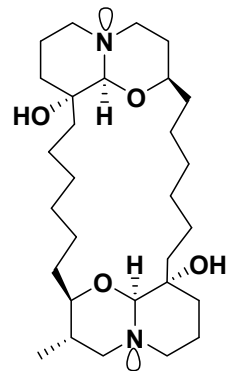

43

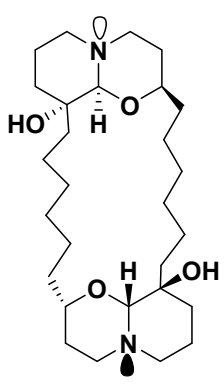

44

Figure 5. Structures of 17-44.

(+)-7S-Hydroxyxestospongin A (27) [25], demethylxestospongin B (28) [26], and C (29) were isolated from Xestospongia sp. [27]. Compound 28 was also isolated from Neopetrosia exigua, along with a quinolizidine derivative, $9^{\prime}$-epi-3 $\beta, 3^{\prime} \beta$-dimethylxestospongin $C$ (30) [28]. Compounds 28-30 showed cytotoxic activity with $\mathrm{ED}_{50}$ values of $0.8,2.0$, and $0.2 \mu \mathrm{g} / \mathrm{mL}$ against $\mathrm{L} 1210$ (mouse lymphocytic leukemia) and $\mathrm{ED}_{50}$ values of 2.5, 2.5, and $2.0 \mu \mathrm{g} / \mathrm{mL}$ against $\mathrm{KB}$ (human epidermoid carcinoma) cells, respectively [26]. 
Araguspongines B (31), C (32), F-H (33-35), and J (36) (Figure 5) were isolated from the Okinawan sponge Xestospongia sp. [29]. A bis-1-quinolizidine derivative, $3 \alpha$-methylaraguspongine (37), along with 17, 19, 20, and 32, were isolated from Xestospongia exigua [30].

On the basis of molecular modeling and NMR spectroscopy, Hoye et al. re-examined the chemical structures of several members of araguspongine/xestospongin families of alkaloids [31]. They studied the cis- vs. trans-decalin-like conformers and the relative configuration of various substituted 1-oxaquinolizidine-containing macrocycles. They found that (i) for the unsubstituted parent compound 1-oxaquinolizidine, the trans-decalin-like isomer is the dominant contributor based on ${ }^{1} \mathrm{HNMR}$ studies (up-field chemical shift value for the $\mathrm{N}-\mathrm{CH}-\mathrm{O}$ proton $(\delta 3.41)$, consistent with two sets of anti-periplanar non-bonding electrons to $\mathrm{C} 9-\mathrm{Ha} 9$, along with coupling constant values $(J)$, fit the dihedral angle of trans-like isomer), and (ii) trans-dialkylated ring substitutions are largely common in the trans-decalin-like conformation, while trans-dialkylated ring substitutions are largely common in the trans-decalin-like conformation, and dialkylated ring substitutions are largely common in the cis-decalin-like conformation [31]. The thermodynamic stability of these conformations was due to the trans-dialkylated orientation and the presence of a cis-decalin-like structure, which provide more stability by their anomeric effect [32].

In 2002, two new $\mathrm{N}$-oxide araguspongines, araguspongines $\mathrm{K}$ (38) and L (39), along with 17, were isolated from the Red Sea sponge Xestospongia exigua [33]. Both 38 and 39 exhibited cytotoxicity against HL-60 cells with an $\mathrm{IC}_{50}$ value of $5.5 \mu \mathrm{M}$, whereas 17 showed an $\mathrm{IC}_{50}$ value of $5.9 \mu \mathrm{M}$ [33]. Later on, Liu et al. isolated araguspongine $\mathrm{M}$ (40), along with 17 and 31, from the same sponge [34].

Three compounds, identified as LT-9 (41), LT-10 (42), and LT-6 (43) (Figure 5), were isolated from the Thai water sponge Xestospongia sp.; however, their structures were clarified and renamed as araguspongines N-P (41-43) [20,35]. Araguspongines A, B, C, F, G, H, and J (20, 31, 32, 33, 34, 35, and 36) and M-P (40-43) possess bis-1-oxaquinolizidine moiety, whereas 38 and 39 have a bis-1-oxaquinolizidine $N$-oxide moiety $[17,33]$. The biological activities of araguspongines include antifouling, cytotoxic, antitubercular, antimalarial, somatostatin, and vasoactive intestinal peptide inhibitory effects $[33,36]$.

Dung et al. reported the isolation of meso-araguspongine $C(44)$ from the sponge Xestospongia muta. Compounds 32 and 44 showed significant cytotoxic activity against LU-1, HepG-2, HL-60, MCF-7, and SK-Mel-2 human cancer cells, with $\mathrm{IC}_{50}$ values ranging from 0.43 to $1.02 \mu \mathrm{M}$; however, 44 is more potent than 32 [20]. Compounds 20, 32, 38, and 39 exhibited cytotoxicity against breast cancer BT-474 cells, with $\mathrm{IC}_{50}$ values of $9.3,15.2,29.5$, and $35.6 \mu \mathrm{M}$, respectively [37].

Araguspongines show significant antifouling activity with low toxicity against both micro- and macrofouling organisms [33,36]. Their potent antibacterial activity has been shown against seven strains of fouling bacteria i.e., Pseudomonas aeruginosa, Pseudomonas putida, Pseudomonas chlororaphis, Pseudoalteromonas haloplanktis, Bacillus cereus, Bacillus pumilus, and Bacillus megaterium by a fraction of bis-1-oxaquinolizidine alkaloids [36].

Araguspongines that possess a macrocyclic ring with two cis- or trans-dialkylated orientations at C-2 and C-9 on both 1-oxaquinolizidine rings, as well as two trans- or cis-decalin-like rings, showed potent biological activities. For example 31, 32, 33, 40, and 44 exhibited growth-inhibitory activity against HL-60, with $\mathrm{IC}_{50}$ values ranging from 0.62 to $5.90 \mu \mathrm{g} / \mathrm{mL}$. On the contrary, compounds that have both cis- and trans-dialkylated orientation and one cis-decalin-like ring, or those that possess bis-1-oxaquinolizidine $N$-oxide, showed weak or no activity. This was demonstrated by the fact that 19, 20, and 39 exhibited weak or no biological activity against HL-60 cells, with IC 50 values ranging from 16.79 to $22.95 \mu \mathrm{g} / \mathrm{mL}$ [20]. Compound 27 was inactive against foulant organisms [25]. Therefore, the stability of the aforementioned araguspongines' conformation seems to influence their biological activity.

Compounds 19 and 20, containing one trans- and one cis-decalin-like ring, exhibited weaker activity against HL-60 when compared to other araguspongines [26]. Compound 20 showed moderate 
activity relative to $\mathbf{1 8}$ and $\mathbf{2 8}$ against KB and L1210 cells. This effect might be due to the presence of the $\mathrm{OH}$ group at C-2 in 20 [26].

Compound 18 displaced $\left[{ }^{3} \mathrm{H}\right] \mathrm{IP}_{3}$ from the membranes of cerebellar and skeletal myotube homogenates, with $\mathrm{EC}_{50}$ values of $44.6 \pm 1.1 \mu \mathrm{M}$ and $27.4 \pm 1.1 \mu \mathrm{M}$, respectively [38]. This compound inhibited bradykinin-induced $\mathrm{Ca}^{2+}$ signals of the neuroblastoma cells (NG108-15) and selectively blocks the slow intracellular $\mathrm{Ca}^{2+}$ signal induced by membrane depolarization with high external $\mathrm{K}^{+}(47 \mathrm{mM})$ in rat skeletal myotubes [38]. Compound 18 decreases IP3-induced $\mathrm{Ca}^{2+}$ oscillations, with an $\mathrm{EC}_{50}$ value of $18.9 \pm 1.35 \mu \mathrm{M}$ [38]. Conclusively, 18 showed cell-permeant activity and was a competitive inhibitor of IP3 receptors in cultured rat myotubes, and it separated myonuclei and NG108-15 cells [38].

The organic extract Haliclona exigua exhibited adulticidal and embryostatic actions against human lymphatic filarial parasite B. malayi in an experimental rodent model, and this activity could be due to the presence of araguspongin C [4]. Compound 32 showed potent activity against the Mycobacterium tuberculosis strain $\mathrm{H} 37 \mathrm{Rv}$, with a minimum inhibitory concentration (MIC) value of $3.94 \mu \mathrm{M}$ (positive control: rifampin, $\left.\mathrm{IC}_{50}=0.61 \mu \mathrm{M}\right)$ [33].

Compound 32 displayed an in vitro anti-proliferative effect against multiple breast cancer cell lines in a dose-dependent manner. It causes the induction of autophagic cell death in HER2-overexpressing BT-474 breast cancer cells, which was characterized by vacuole formation and upregulation of autophagy markers. It displayed autophagy associated with the inhibition of c-Met and HER2 receptor tyrosine kinase activation. Compound 32 also suppressed the depression of the PI3K/Akt/mTOR signaling cascade in the breast cancer cells that undertake autophagy. The induction of autophagic death in BT-474 cells was associated with reduced levels of the inositol 1,4,5-trisphosphate receptor upon management with an effective concentration of 32 [37].

\subsection{Macrocycles Containing a 3-Alkylpiperidine Moiety}

\subsubsection{Pentacyclic Derivatives}

Saraines/Sarains

An investigation of the marine sponge Reniera sarai led to the identification of saraines 1-3 (45-47) [39], which belong to the 3-alkylpiperidine subclass (Figure 6). The complexity of their structures delayed a complete elucidation until the mid-1980s.

The main scaffold of saraines consists of a tetrahydropyridine moiety attached to a trans-2-oxoquinolizidine ring system. They possess a pentacyclic skeleton that includes a trisubstituted alkene and a carbonyl group. The two cycles are supplied by linking the two heterocyclic systems with linear alkyl chains [39]. The three stereoisomers of saraines 1-3 have been reported and identified as isosaraines 1-3 (48-50) [40-42], which were also isolated from $R$. sarai as minor components. Saraines A-C (51-53) were isolated from the Mediterranean sponge $R$. sarai and possess an entirely different structure from those of the previously reported saraines 1-3 (45-47) and isosaraines 1-3 (48-50). The entire skeleton of 51-53 is composed of two piperidine rings condensed to form a central nucleus, which linked to a pair of alkyl chains [43,44]. Compounds $\mathbf{4 5 - 4 7}$ and 51-53 (Figure 6) exhibited antibacterial activity against $S$. aureus with MIC values between 6.25 and $50 \mu \mathrm{g} / \mathrm{mL}$; a lethality against Aspergillus salina, with $\mathrm{LD}_{50}$ values between 2.5 and $46.7 \mu \mathrm{g} / \mathrm{mL}$; an inhibitory effect against potato disc infected with Aspergillus tumefaciens, with inhibition percentages between $16 \%$ and $55 \%$; and inhibition of the development of fertilized sea urchin eggs, with $\mathrm{IC}_{50}$ values between 1.56 and $6.25 \mu \mathrm{g} / \mathrm{mL}$. However, 45 showed neither antimicrobial activity nor the inhibition of development of fertilized sea urchin eggs at a concentration as high as $50 \mu \mathrm{g} / \mathrm{mL}$ [45]. Overall, saraines show an increase in biological activity with an increase in the size of the macrocyclic ring (A) within the two groups from 45 to 47 and from 51 to 53 (Figure 6). 

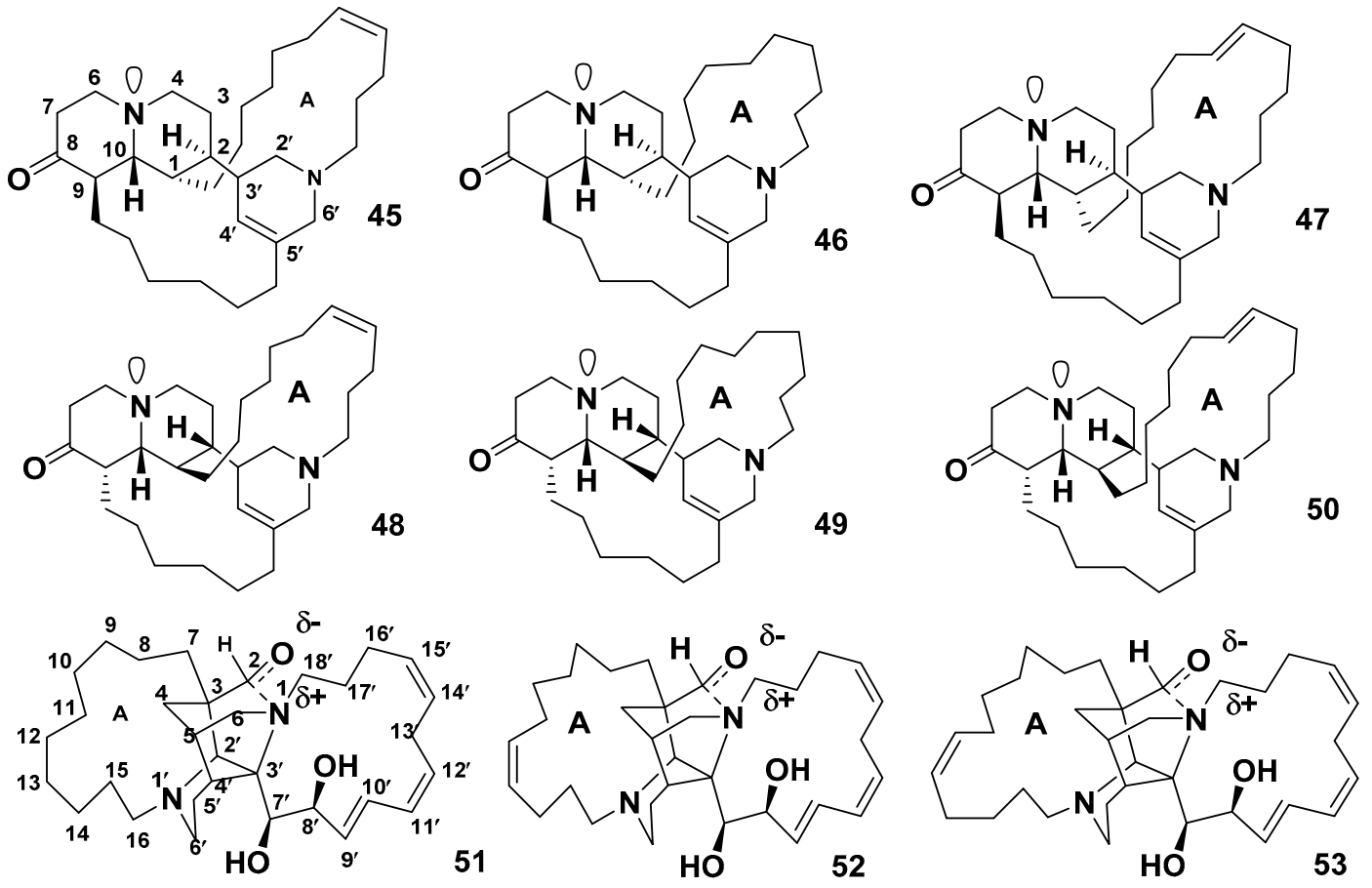

Figure 6. Structures of 45-53.

Madangamines

Madangamines A (54) [46] and B-E (55-58) [47] were isolated from the marine sponge X. ingens, whereas madangamine F (59) was isolated from the sponge Pachychalina alcaloidifera [48]. Because of their diazatricyclic skeleton and two peripheral macrocyclic rings, madangamines have an unusual chemical structure. The macrocyclic ring D in madangamines varies in size, ranging from 13 to 15 carbon atoms. The ring $\mathrm{E}$ in $\mathbf{5 4 - 5 8}$ is an 11-membered ring with two double bonds, whereas $\mathbf{5 9}$ possesses a 13-membered ring with four double bonds [49] (Figure 7).
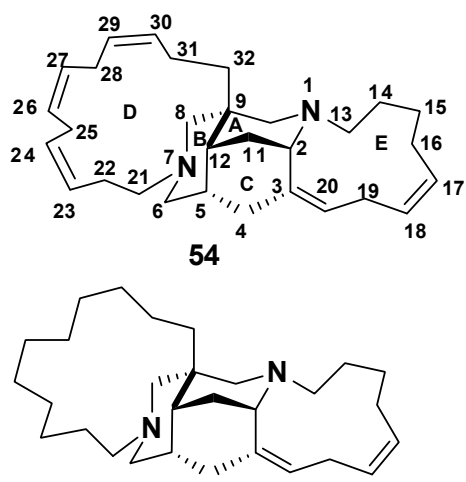

57

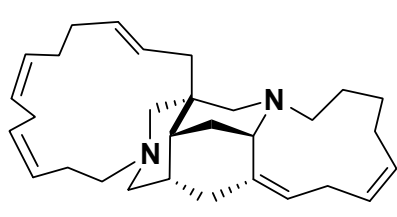

55

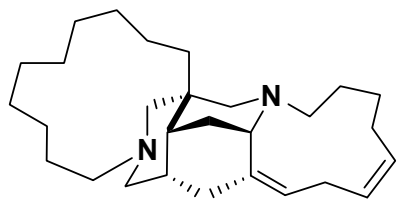

58

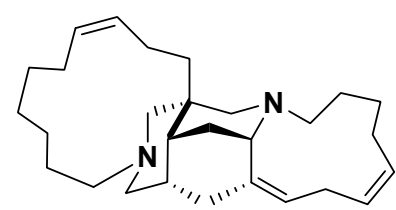

56

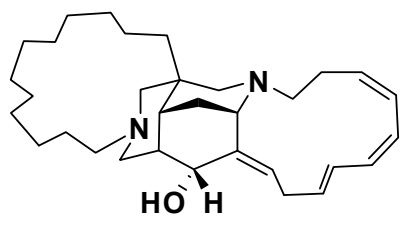

59

Figure 7. Structures of 54-59.

Compound 54 displayed significant in vitro cytotoxicity toward murine leukemia P388 (ED 50 value of $0.93 \mu \mathrm{g} / \mathrm{mL}$ ), lung A549 (ED 50 value of $14 \mu \mathrm{g} / \mathrm{mL}), \mathrm{MCF}-7$ (ED 50 value of $5.7 \mu \mathrm{g} / \mathrm{mL}$ ), and brain U373 (ED 50 value of $5.1 \mu \mathrm{g} / \mathrm{mL})$ cancer cell lines, respectively [46]. Compound 59 showed weak cytotoxicity, with $\mathrm{EC}_{50}$ values of 16.7, 19.8, >25, and $16.2 \mu \mathrm{g} / \mathrm{mL}$ against HL-60, SF 295 (human CNS), HCT-8 (colon), and MDA-MB435 (melanoma) cancer cell lines, respectively [48]. 


\section{Haliclonadiamines}

The bis-indane macrocycles (10E,12Z)-haliclonadiamine (60) and (10Z,12E)-haliclonadiamine (61) were isolated from Halichondria panicea [50], whereas papuamine (62) [51] and haliclonadiamine (63) [52] were isolated from Haliclona sp. Compounds 60-63 showed a potent effect against Mycobacterium smegmatis with inhibitory zones of 7-16 mm at a concentration of $10 \mu \mathrm{g} / \mathrm{disc}$ [53]. Compound 63 exhibited a potent effect with an inhibition zone of $16 \mathrm{~mm}$ at $10 \mu \mathrm{g} / \mathrm{disc}$. SAR analysis suggests that the antitubercular activity of these compounds favors the 13-membered ring $E$ and the 10E,12E configuration [53] (Figure 8). Recently, Liu et al. have revised the structure of 63 using X-ray crystallography, establishing the absolute configurations of the stereogenic carbons as $1 S, 3 R, 8 S, 9 R, 15 S, 20 R, 22 R(\mathbf{6 4})$, which are opposite to those previously reported for 63 [54].

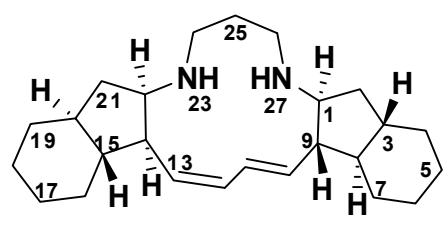

60

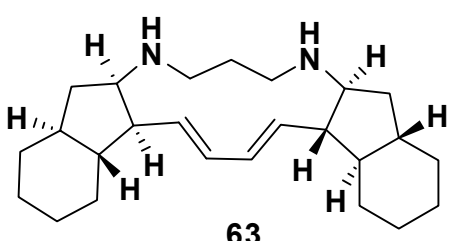

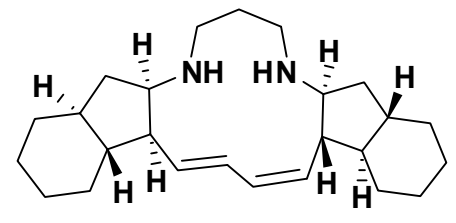

61

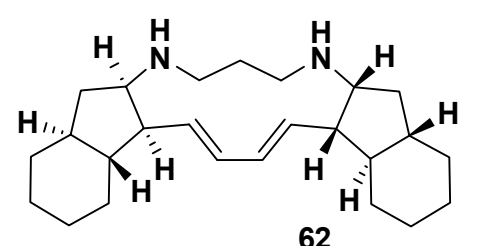

62<smiles>[R4]#C/C=C/[C@H]1[C@H]2CCCC[C@H]2C[C@H]1NCCCN[C@H]1C[C@H]2CCCC[C@H]2[C@H]1C</smiles>

64

Figure 8. Structures of $60-64$.

Ingenamines and Ingamines

Ingamines A (65) and B (66) [55], ingenamine A (67) [56], and ingenamines B-F (68-72) [57] were all isolated from $X$. ingens, whereas ingenamine G (73) was isolated from the sponge Pachychalina sp. [8]. Meanwhile, dihydroingenamine D (74) and 22(S)-hydroxyingamine A (75) were isolated from the sponge Petrosid Ng5 Sp5 [58] (Figure 9). Compounds 63, 74, and 75 exhibited antiplasmodial activity against chloroquine-resistant (W2) and chloroquine-sensitive (D6) strains of Plasmodium falciparum, with $\mathrm{IC}_{50}$ values of 57 and $72 \mathrm{ng} / \mathrm{mL}$ for 63,78 and $90 \mathrm{ng} / \mathrm{mL}$ for 74 , and 140 and $200 \mathrm{ng} / \mathrm{mL}$ for 75, respectively [58]. Compound 73 exhibited cytotoxic activity, with $\mathrm{IC}_{50}$ values of $11.3,9.8$, and $8.6 \mu \mathrm{g} / \mathrm{mL}$ against MCF-7, B16 (leukemia), and HCT-8 cancer cells, respectively [8]. Moreover, this compound showed antimicrobial activity with MIC values at $8 \mu \mathrm{g} / \mathrm{mL}$ against $M$. tuberculosis $\mathrm{H} 37 \mathrm{Rv}, 105 \mu \mathrm{g} / \mathrm{mL}$ against $S$. aureus (ATCC 25923), $75 \mu \mathrm{g} / \mathrm{mL}$ against $E$. coli (ATCC 25922), and with MIC values ranging from 10 to $50 \mu \mathrm{g} / \mathrm{mL}$ against two of four strains of oxacillin-resistant S. aureus [8]. Xestocyclamine (76) is a pseudo-enantiomeric to $\mathbf{6 7}$, and they differ only in the location of the carbon-carbon double bond in the 11-membered ring. Compound $\mathbf{7 6}$ exhibited moderate inhibitory activity against protein kinase $\mathrm{C}$, with an $\mathrm{IC}_{50}$ value of $4 \mu \mathrm{g} / \mathrm{mL}$. Interestingly, 76 showed selectivity against IL-1 (interleukin), as it showed no activity against other cancer-relevant targets [59]. 


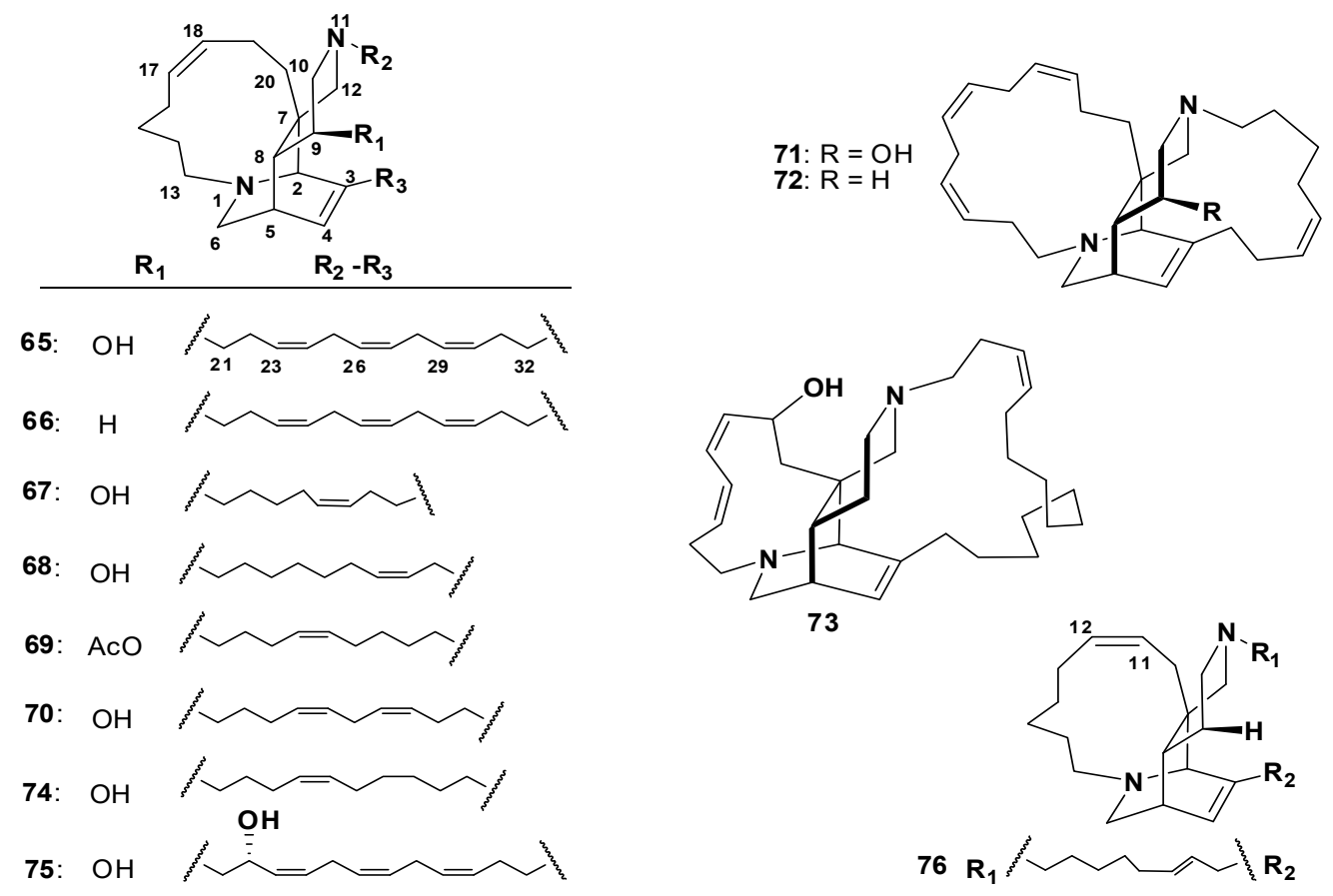

Figure 9. Structures of 65-76.

\subsubsection{Tetracyclic Derivatives}

Halicyclamines

Halicyclamines A (77) and (-) halicyclamine B (78) were isolated from Haliclona sp. [60] and Xestospongia sp. [61], respectively (Figure 10). Haliclonacyclamines A (79) and B (80) [62] were isolated from Haliclona sp. 22-Hydroxyhaliclonacyclamine B (81) [63], 2-epi-tetradehydro haliclonacyclamine (82), tetradehydrohaliclonacyclamine A mono- $N$-oxide (83), and tetradehydrohaliclonacyclamine A (84) were isolated from Halichondria sp. [64]. The anti-dormant mycobacterial activity of 77 was reported by Kobayashi et al., with the correlation of Ded A Protein to the mechanism of action of 77 under dormancy-inducing hypoxic and standard aerobic growth conditions [65]. Compound 78 showed weak and selective antimicrobial activity and also exhibited growth inhibitions of $50 \%$ and $20 \%$ at $200 \mu \mathrm{g} /$ disk against Bacillus subtilis and E. coli, respectively, but showed no activity toward C. albicans [61]. Compound 79, isolated from the Haliclona sponge of the Solomon Islands, exhibited a great antiplasmodial effect in vivo and in vitro against Plasmodium vinckei petteri-infected mice and the chloroquine-resistant $P$. falciparum strain FCB1. It also shows IC $_{50}$ values of 0.052 and $0.33 \mu \mathrm{g} / \mathrm{mL}$ against the $P$. falciparum strain FCB1 and chloroquine-sensitive 3D7, respectively [66]. In vitro, 79 displayed cytotoxicity against MCF-7 cells $(2.6 \mu \mathrm{g} / \mathrm{mL})[66]$.

Haliclonacyclamines C (85) and D (86) were isolated from a specimen of Haliclona sp. collected from Heron Island on the Great Barrier Reef [67].

Haliclonacyclamine E (87) was isolated from the Haplosclerida sponge Arenosclera brasiliensis, which is endemic to the Southeastern coast of Brazil [68]. Compound 87 displayed cytotoxicity against HL60, B16, L929 (brosarcoma), and U-138 (colon) cancer cell lines, with $\mathrm{IC}_{50}$ values of 4.23, 1.82, 3.89 , and $6.06 \mu \mathrm{g} / \mathrm{mL}$, respectively [69]. Haliclonacyclamine F (88) was isolated from the sponge $P$. alcaloidifera. Compound 88 exhibited cytotoxicity against HL-60, SF 295, HCT-8, and MDA-MB435 cancer cell lines with $\mathrm{IC}_{50}$ values of 2.2, 4.5, 8.6, and $1.0 \mu \mathrm{g} / \mathrm{mL}$, respectively [48]. Halichondramine (89) was isolated from the Red Sea sponge Halichondria sp. [70].

A bis-piperidine alkaloid, neopetrosiamine A (90), isolated from Neopetrosia proxima, showed potent inhibitory activity against MCF-7, CCRF-CEM (leukemia), and MALME-3M melanoma cancer cells, with $\mathrm{IC}_{50}$ values of 3.5, 2.0, and $1.5 \mu \mathrm{M}$, respectively. Compound 90 also exhibited in vitro 
cytotoxicity, with an MIC value of $7.5 \mu \mathrm{g} / \mathrm{mL}$, toward a pathogenic strain of $M$. tuberculosis $\left(\mathrm{H}_{37} \mathrm{Rv}\right)$ in a microplate Alamar Blue assay (MABA). Additionally, 90 showed antiplasmodial activity against $P$. falciparum, with an $\mathrm{IC}_{50}$ value of $2.3 \mu \mathrm{M}$ [71]. Although 78 and 90 have very similar structural features, with one of the alkyl chains of $\mathbf{9 0}$ being shorter than that of $\mathbf{7 8}$ and exhibiting stronger activity against P. falciparum than 78, 78 showed higher activity than 90 against MCF7 breast cancer cells [71].

Tetradehydrohalicyclamine B (91) and 78 were isolated from the sponge Acanthostrongylophora ingens. Both compounds showed inhibition against the constitutive proteasome and immunoproteasome. Compound 78 revealed 4- to 10-fold higher inhibitory activity than 91 [72].

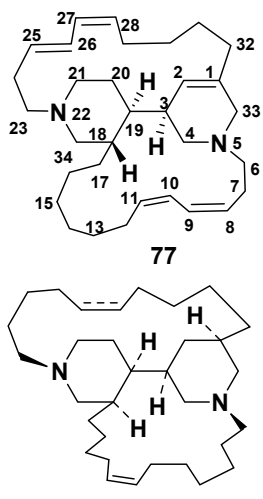

80: $27,28=$ 86: $27,28 \mathrm{H}, \mathrm{H}$
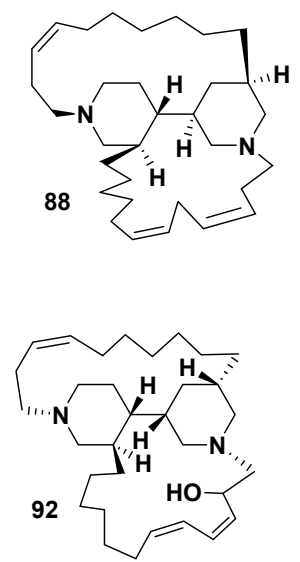
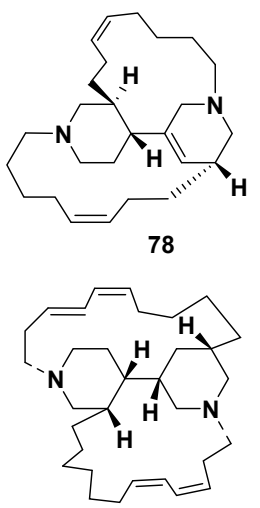

82: $2 \alpha-\mathrm{H}$ 84: $2 \beta-H$

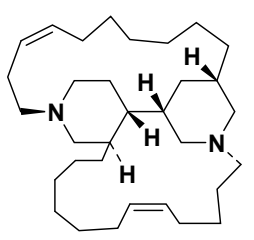

89

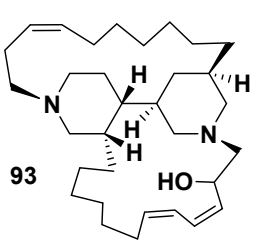

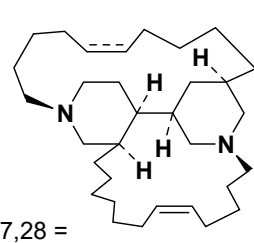

85: $27,28 \mathrm{H}, \mathrm{H}$

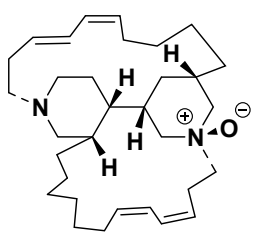

83
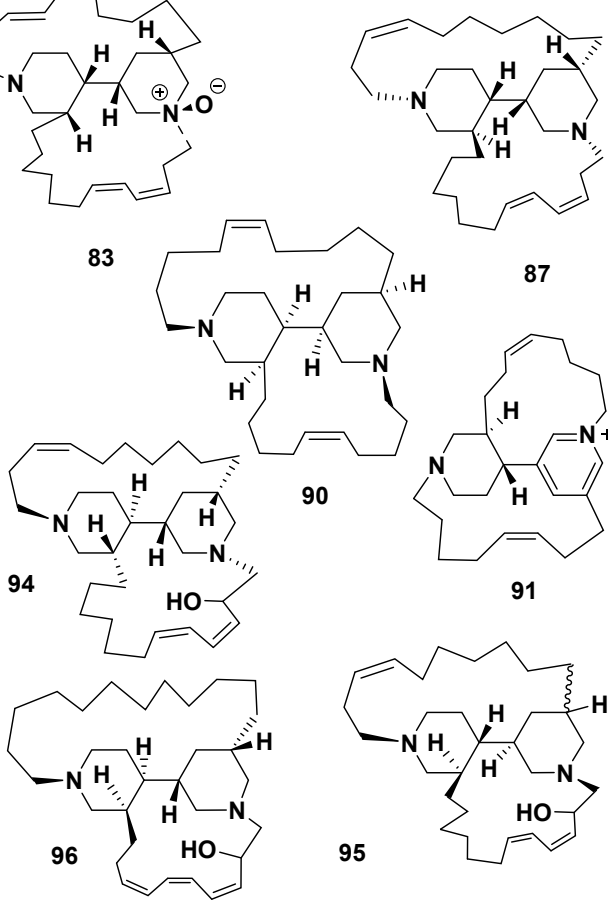

87

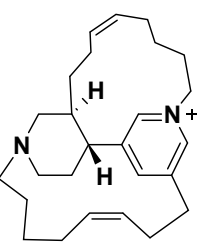

91

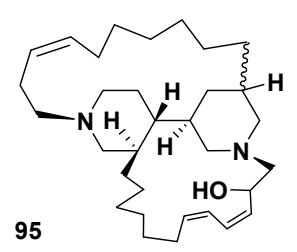

Figure 10. Structures of 77-96.

Arenosclerins

Arenosclerins A-C (92-94) were isolated from the Brazilian endemic Haplosclerida sponge, A. brasiliensis [68], whereas arenosclerins D (95) and E (96) (Figure 10) were isolated from the sponge $P$. alcaloidifera [48]. Although these compounds were inactive against C. albicans, 92 and 94 showed antibacterial activity against a larger number of bacteria strains than 93; however, potent antibacterial activity was exhibited by both 93 and $\mathbf{9 4}$. Moreover, these compounds showed potent toxicity toward HL-60, B16, L929, and U-138 cancer cell lines [69]. The $\mathrm{IC}_{50}$ values of 92 were 1.77, 2.34, 4.31, and 3.83 $\mu \mathrm{g} / \mathrm{mL}$; of 93 were 1.76, 2.24, 4.07, and $3.62 \mu \mathrm{g} / \mathrm{mL}$; and of 94 were 1.71, 2.17, 3.65, and $3.60 \mu \mathrm{g} / \mathrm{mL}$ against B16, L929, HL-60, and U-138 cancer cell lines, respectively [69].

Compounds 95 and 96 were tested for their cytotoxicity against HL-60, SF 295, HCT-8, and MDA-MB-435 cancer cell lines, and their $\mathrm{IC}_{50}$ values were $2.1,5.9,6.2$, and $1.2 \mu \mathrm{g} / \mathrm{mL}$ and 6.9, 8.7, >25, and $3.1 \mu \mathrm{g} / \mathrm{mL}$, respectively [48]. 


\subsection{Manzamines}

\subsubsection{Pentacyclic Manzamines}

Pentacyclic manzamines are a group of macrocyclic alkaloids containing a $\beta$-carboline moiety attached to pentacyclic rings with a double bond between C-10 and C-11 in the eight-membered ring $[73,74]$.

Manzamine A hydrochloride salt (97), the first reported member of manzamines, was isolated from Haliclona sp. [75]. This compound was also isolated from Pellina sp. and was named keramamine A [76]. Compound 97 showed a broad spectrum of biological effects, i.e., potent antipathogenic activity against Leishmania donovani, antimycobacterial activity [77], cytotoxicity against pancreatic cancer (by inhibiting autophagy) [78], P388 [75], human colorectal carcinoma [79], and anti-Alzheimer activity [80]. It also exhibited an inhibitory effect against herpes simplex virus (HSV-1) [81] and HSV-2 [82], human immunodeficiency virus (HIV) [77], as well as the rodent malaria parasite Plasmodium berghei in vivo [10].

8-Hydroxymanzamine A (98, also known as manzamine G or manzamine $\mathrm{K})$ was isolated from Pachypellina sp. and the stereochemistry of $\mathbf{9 8}$ was the same as $\mathbf{9 7}$ (Figure 11), as both of them were dextrorotatory. Compounds $\mathbf{9 7}$ and $\mathbf{9 8}$ exhibited moderate antitumor activity against KB and LoVo (colon) cancer cell lines and anti-HSV-II (herpes simplex) activity [82]. Compounds 97 and 98 displayed in vitro and in vivo antimalarial effects against $P$. berghei. The percentage of the asexual erythrocytic stages suppression, which registered after a single intraperitoneal injection of $\mathbf{9 7}$ and $\mathbf{9 8}$ administered to infected mice, was $90 \%$. These compounds increased the time of living of the infected mice to more than $240 \mathrm{~h}$, using just one dose of $97(50 \mathrm{mM} / \mathrm{kg})$ and $98(100 \mathrm{mM} / \mathrm{kg})$ [83].

3,4-Dihydromanzamine A (99) and 6-hydroxymanzamine A (manzamine Y) (100), isolated from a marine sponge Amphimpdon sp., showed antibacterial activity against a Gram-positive bacterium, Sarcina lutea (MIC values of 4 and $1.25 \mu \mathrm{g} / \mathrm{mL}$, respectively). These compounds also exhibited in vitro cytotoxicity against $\mathrm{L} 1210$ ( $\mathrm{IC}_{50}$ values of 0.48 and $1.5 \mu \mathrm{g} / \mathrm{mL}$, respectively) and $\mathrm{KB}$ cells ( $\mathrm{IC}_{50}$ values of 0.61 and $2.5 \mu \mathrm{g} / \mathrm{mL}$, respectively) [84].

1,2,3,4-Tetrahydro-8-hydroxymanzamine A (8-hydroxymanzamine D) (101), and 1,2,3,4-tetrahydro2-N-methyl-8-hydroxymanzamine A (8-hydroxy-2- $N$-methylmanzamine D) (102) (Figure 11) were isolated from the marine sponges of the genera Petrosia and Cribochalina [85]. Compound 102 is cytotoxic toward P388 cell line, with an $\mathrm{ED}_{50}$ value of $0.8 \mu \mathrm{g} / \mathrm{mL}$ [85]. Manzamine $\mathrm{D}(1,2,3,4$-tetrahydromanzamine A) (103) was isolated from Ircinia sp. [86], whereas 3,4-dihydro-6-hydroxymanzamine A (104) and manzamine M (105) were isolated from Amphimedon sp. [87]. Compound 105 was the first reported manzamine congener with a hydroxyl group on the C13-C20 chain. Compounds 104 and 105 showed cytotoxicity against L1210 cells ( $\mathrm{IC}_{50}$ values of 0.3 and $1.4 \mu \mathrm{g} / \mathrm{mL}$, respectively). Moreover, 104 and 105 exhibited antibacterial activity against Sarcina lutea (MIC values of 6.3 and $2.3 \mu \mathrm{g} / \mathrm{mL}$, respectively) and Corynebacterium xerosis (MIC values of 3.1 and $5.7 \mu \mathrm{g} / \mathrm{mL}$, respectively) [87]. Bioassay-directed fractionation of the $\mathrm{CH}_{2} \mathrm{Cl}_{2}$ crude extract of the Palaun sponge, employing an assay for the inhibitors of methionine aminopeptidase-2 (Met AP-2), led to the identification of N-methyl-epi-manzamine $\mathrm{D}$ (106) and epi-manzamine D (107) [88]. Neither of these compounds exhibited selectivity in the yeast assay for inhibitors of Met AP-2; however, both compounds showed cytotoxicity against HeLa and B16F10 melanoma cells. Compound 106 showed strong activity against the B16F10 cell line [88]. 12,34-Oxamanzamine A (108) was isolated from an Indo-Pacific sponge identified as 011ND 51 [89]. This compound possesses an unusual ring system due to the presence of an ether bridge formed between C-12 and C-34 of the typical manzamine structure. Compound $\mathbf{1 0 8}$ displayed less activity against malaria and the AIDS OI pathogen, $M$. tuberculosis, compared to the other co-isolated manzamines, which might be attributed to the presence of the C12-C34 ether bridge in 108 [89] (Figure 11). ent-8-Hydroxymanzamine A (109) was isolated from an undescribed genus of an Indo-Pacific sponge. It exhibited improved activity against P-388, with an $\mathrm{IC}_{50}$ value of $0.25 \mu \mathrm{g} / \mathrm{mL}$ [90]. Compound 109 displayed in vitro growth inhibitory effect against Trypanosoma gondii and host cell with 71\% 
and 38\% inhibition, respectively, at a concentration of $1 \mu \mathrm{M}$ [90]. 12,28-Oxamanzamine $\mathrm{A}(\mathbf{1 1 0})$ and 12,28-oxa-8-hydroxymanzamine A (111) were isolated from two collections of an Indo-Pacific sponge. These compounds contain a novel manzamine-type ring system, generated through a new ether bridge formed between C-12 and C-28 or between C-12 and C-34 of the typical manzamine structure. These compounds exhibited potent anti-inflammatory, antifungal, and anti-HIV-1 activities [91].
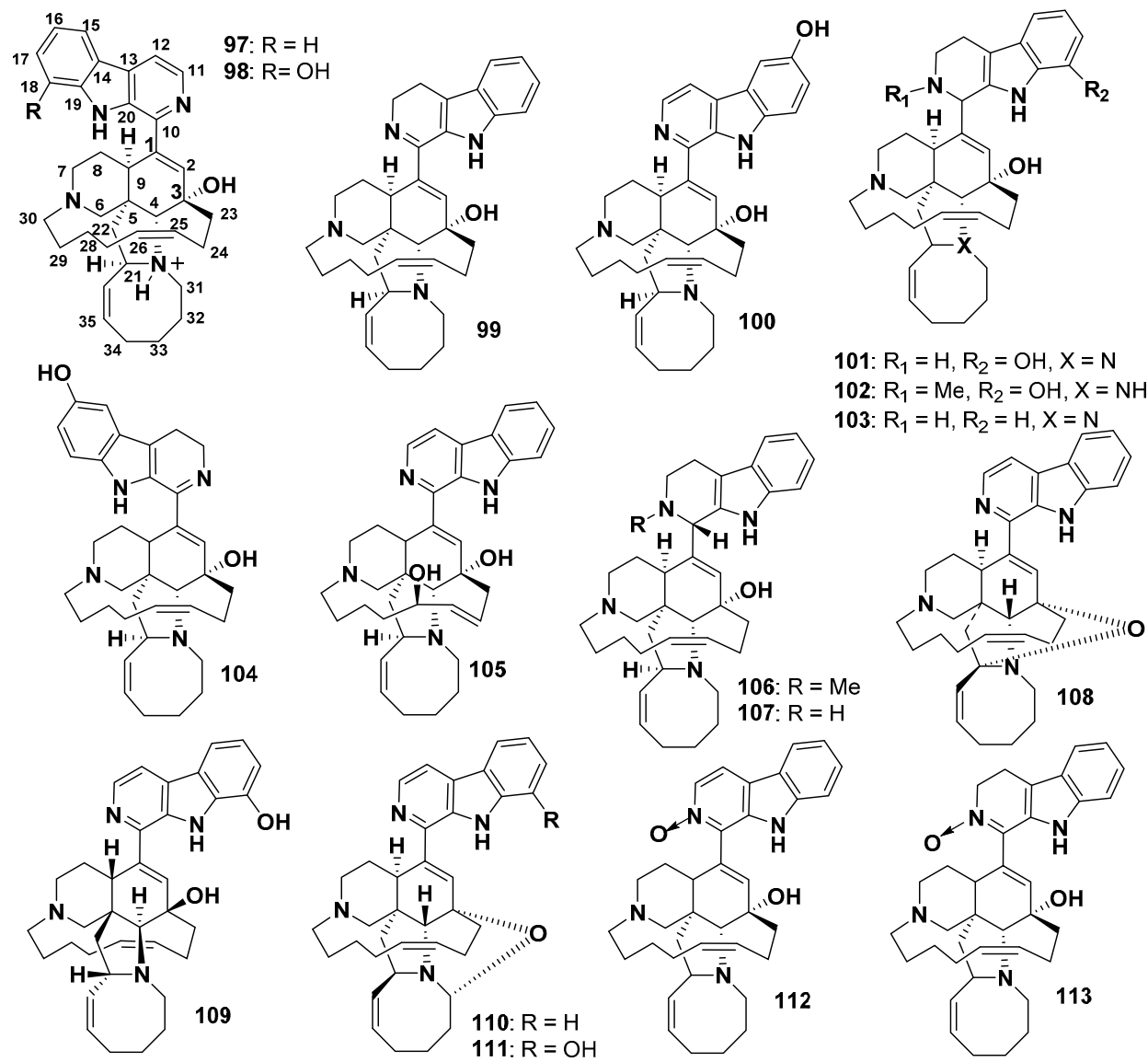

103: $R_{1}=H, R_{2}=H X=N$
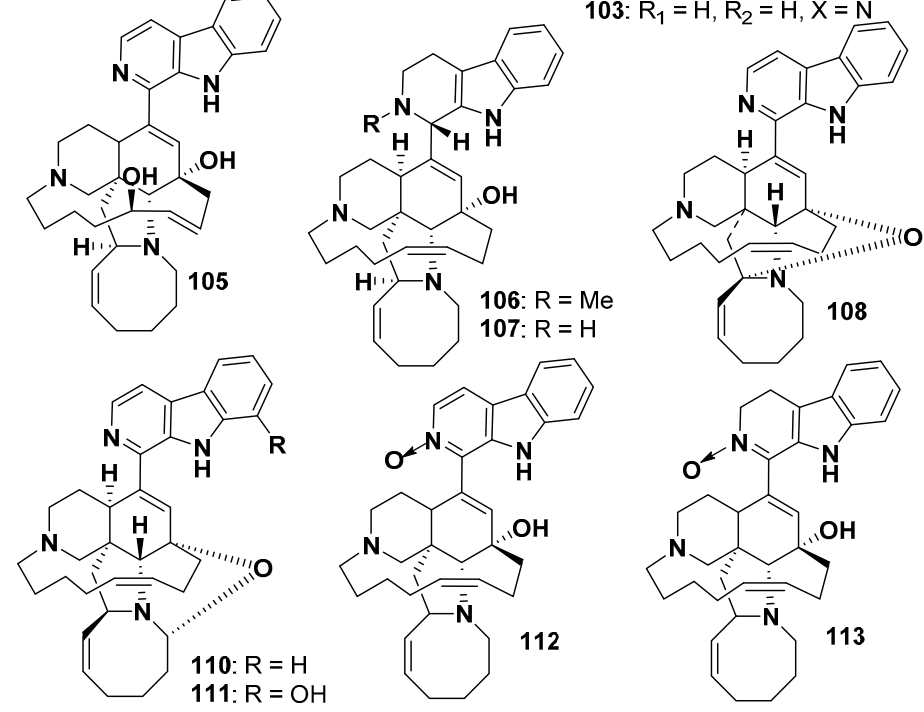

Figure 11. Structures of $\mathbf{9 7 - 1 1 3 . ~}$

Manzamine A N-oxide (112) and 3,4-dihydromanzamine A $N$-oxide (113) were isolated from the Indonesian marine sponge Xestospongia ashmorica [92]. Compound 112 showed potent cytotoxicity against L5178Y mouse lymphoma cells with an ED $_{50}$ of $1.6 \mu \mathrm{g} / \mathrm{mL}$ [92].

Acanthomanzamines A (114) and B (115), isolated from A. ingens, contain a tetrahydroisoquinoline ring system instead of $\beta$-carboline. Compounds 114 and 115 showed potent cytotoxicity against HeLa cells, with $\mathrm{IC}_{50}$ values of 4.2 and $5.7 \mu \mathrm{M}$, respectively. Interestingly, 114 and 115 (Figure 12) exhibited stronger cytotoxicity against HeLa cancer cell line, but less potent proteasome inhibitory activity than their co-isolated $\beta$-carboline-containing manzamines, acanthomanzamines D and E [93]. Several other examples of $\beta$-carboline-based manzamines were also reported from different sponge species. Examples of these are pre-neo-kauluamine (116) from A. ingens [94], zamamidine C (117) [95], zamamidine D (118) [96], nakadomarin A (119) from Amphimedon sp. [97], ircinol A (120) from Amphimedon sp. [98], ircinal A (121) from Ircinia sp. [86], ircinal E (122) from A. ingens [99], and 12,28-oxaircinal A (123) from Acanthostrongylophora sp. [100]. The reported biological activities of the aforementioned compounds were quite interesting, Compound 116 showed proteasome inhibitory activity [94], whereas 117 displayed potent antitrypanosomal effect against Trypanosoma brucei brucei and antimalarial activity against $P$. falciparum [95]. Compound 118 exhibited antimicrobial activity against several strains of fungi and bacteria [96], whereas 119 exhibited antimicrobial effects against C. xerosis and Trichophyton mentagrophytes, with MIC values of 11 and $23 \mu \mathrm{g} / \mathrm{mL}$, respectively [97]. Compound 120 inhibited 
endothelin-converting enzyme, with an $\mathrm{IC}_{50}$ of $55 \mu \mathrm{g} / \mathrm{mL}$ [98]. Compound 121 displayed cytotoxicity against $\mathrm{L} 1210$ and $\mathrm{KB}$ cancer cells with $\mathrm{IC}_{50}$ values of 1.4 and $4.8 \mu \mathrm{g} / \mathrm{mL}$, respectively [86]. Compound 122 showed weak cytotoxicity and L5178Y (murine lymphoma) cells with an $\mathrm{IC}_{50}$ value of $21.7 \mu \mathrm{g} / \mathrm{mL}$, respectively [99]. Pentacyclic manzamines having a ketonic group in their eight-membered ring instead of a double bond were also reported. Examples of this class of compounds are manzamines $\mathrm{E}$ (124) [76], F (keramamine B) (125) from Xestospongia sp. [101], ent-manzanine F (126) from Petrosia sp. [90], ent-12,34-oxamanzamines $\mathrm{E}$ (127) and $\mathrm{F}$ (128) from the sponge 011ND 35 [89], 12,34-oxamanzamine $\mathrm{E}$ (129) and 6-hydroxymanzamine E (130) from Acanthostrongylophora sp. [77], 12,28-oxamanzamine E (131) and 12,34-oxa-6-hydroxymanzamine E (132) from Acanthostrongylophora sp. [100], and the related manzamine alkaloid 31-keto-12,34-oxa-32,33-dihydroircinal A (133) from the marine sponge of the genus 011ND 35 [91] (Figure 12). Compounds 124 and 125 displayed cytotoxicity toward L5178Y cells, with $\mathrm{ED}_{50}$ values of 6.6 and $2.3 \mu \mathrm{g} / \mathrm{mL}$ ), respectively [92], whereas they showed similar significant cytotoxicity against P388 cells with an $\mathrm{IC}_{50}$ value of $5.0 \mu \mathrm{g} / \mathrm{mL}$ [101]. Compound 126 inhibited $M$. tuberculosis $(\mathrm{H} 37 \mathrm{Rv})$ with an $\mathrm{IC}_{50}<12.5 \mu \mathrm{g} / \mathrm{mL}$ [90]. Compound 127 showed weak inhibitory activity against $M$. tuberculosis with an $\mathrm{IC}_{50}$ value of $128 \mu \mathrm{g} / \mathrm{mL}$, whereas 128 showed significant activity with $\mathrm{IC}_{50} 12.5 \mu \mathrm{g} / \mathrm{mL}$ [89].

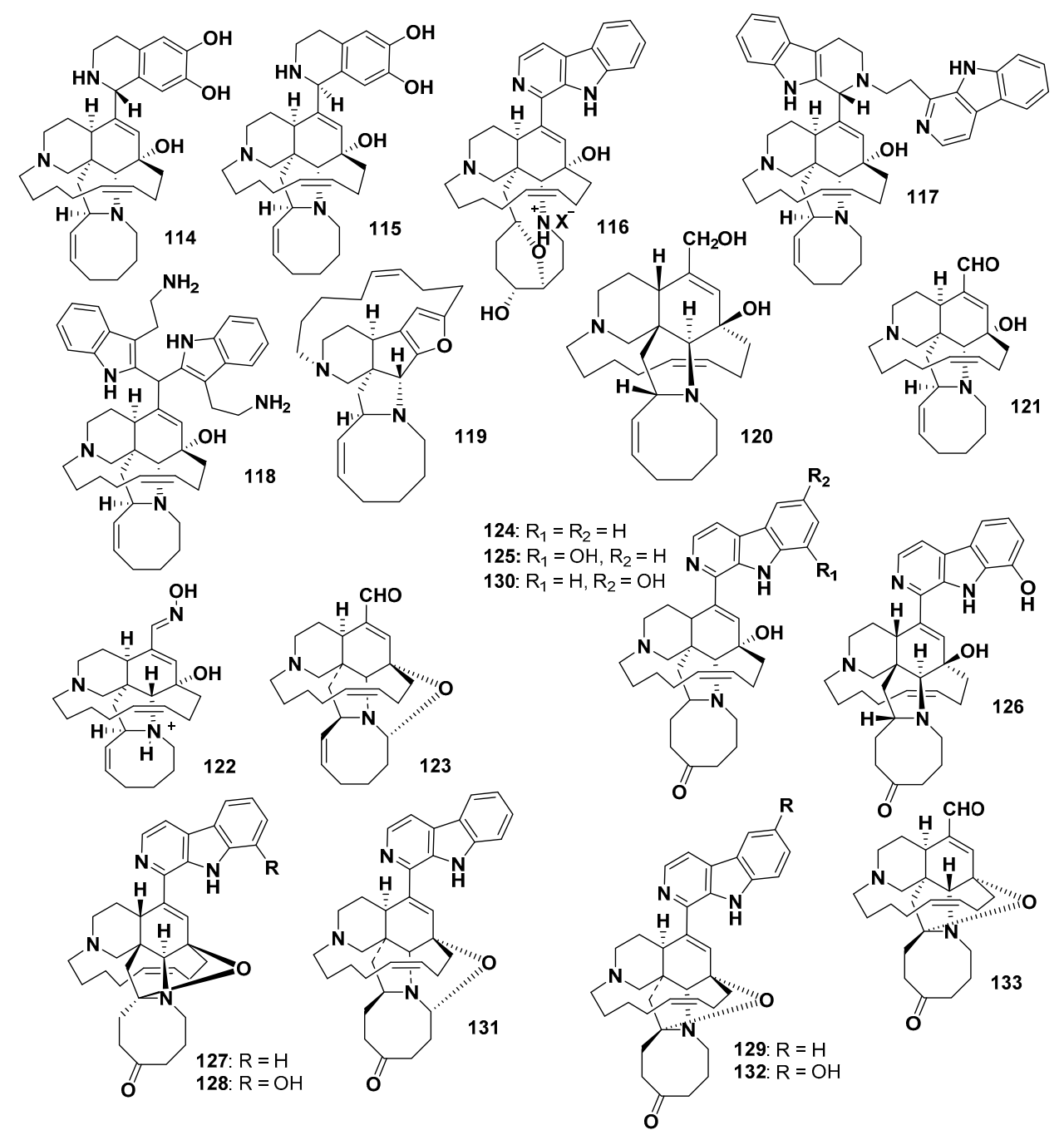

Figure 12. Structures of 114-133. 


\subsubsection{Tetracyclic Manzamines}

Several manzamines containing a $\beta$-carboline ring system linked to a tetracyclic scaffold have been reported. For example, manzamine B (134) was reported from Haliclona sp. [102], manzamines $\mathrm{H}$ (135) and J (136) were isolated from Ircinia sp. [86], manzamine J $N$-oxide (137) was reported from X. ashmorica [92], 8-hydroxymanzamine B (138) was reported from Acanthastrongylophora sp. [100], manzamine L (139) was published from Amphimedon sp. [103], manzamine B N-oxide (140), 3,4-dihydromanzamine B N-oxide (141) and 11-hydroxymanzamine J (142) were reported from Acanthastrongylophora sp. [104], ma'eganedin A (143) was isolated from Amphimedon sp. [105], 8-hydroxymanzamine J (144) was reported from Acanthastrongylophora sp. [77], 3,4-dihydromanzamine J (145) was isolated from Amphimedon sp. [87], acanthomanzamine D (146) and acanthomanzamine E (147) were reported from A. ingens [93], zamamidines A (148) and B (149) were reported from Amphimedon sp. [106], ircinal B (150) was published from Ircinia sp. [86], and ircinol B (151) was reported from Amphimedon sp. [98] (Figure 13).

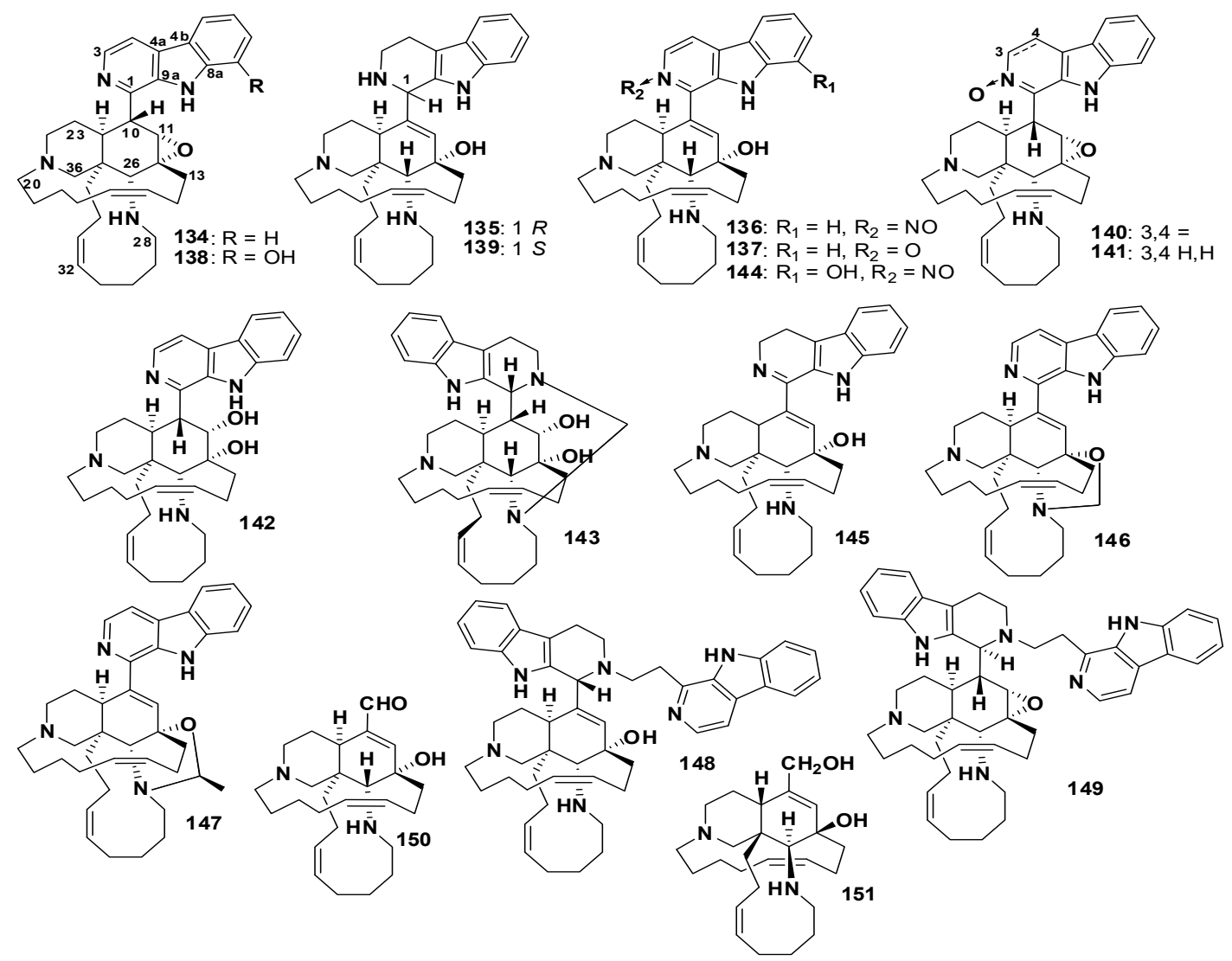

Figure 13. Structures of 134-151.

Compounds $135,136,139,143,145,150$, and 151 showed cytotoxic activity against L1216 cancer cell line with $\mathrm{IC}_{50}$ values of $1.3,2.6,3.7,4.4,5.0,1.9$, and $7.7 \mu \mathrm{g} / \mathrm{mL}$, respectively. Furthermore, 135, 136, 139, 150, and 151 displayed cytotoxicity against $\mathrm{KB}$ cancer cells with $\mathrm{IC}_{50}$ values of $4.6,>10,11.8,3.5$, and $9.4 \mu \mathrm{g} / \mathrm{mL}$, respectively, whereas 137 showed cytotoxicity against L1578Y with IC $_{50}$ values of 1.6 $\mu \mathrm{g} / \mathrm{mL}$, and 148 and $\mathbf{1 4 9}$ showed cytotoxic activity against P388 cells with $\mathrm{IC}_{50}$ values of 13.8 and 14.8 $\mu \mathrm{g} / \mathrm{mL}$, respectively. Compounds 146 and 147 displayed a strong proteasome inhibitory effect, with $\mathrm{IC}_{50}$ values of 0.63 and $1.5 \mu \mathrm{g} / \mathrm{mL}$, respectively [93]. Compounds $\mathbf{1 3 9}$ and $\mathbf{1 4 0}$ showed weak activity against several Gram-positive and Gram-negative bacteria [104]. Compound 143 showed potent activity against Sarcina lutea and B. subtilis, with the same MIC value of $2.8 \mu \mathrm{g} / \mathrm{mL}$ [105]. The reported antimicrobial activity of several manzamines highlights the influence of an eight-membered ring on 
the activity [77]. Moreover, the antitubercular activity is also affected by the ring size; for example, compounds 97 and 136 have similar scaffold, except eight-membered ring in 97 and 11-membered in 136 [83]. Compound 97 exhibited potent anti-tubercular activity against M. tuberculosis (H37Rv) than 136 [83].

\subsubsection{Monomacrocycle Containing Manzamines and Related Compounds}

Compounds in this group have one macrocyclic ring of different sizes, namely, 10-, 11-, 13-, 14and 15-membered rings. Manzamine C (152) was initially isolated from the Okinawan sponge Haliclona sp. This compound possesses an 11-membered heterocyclic ring containing a nitrogen atom [102]. Compound 152 exhibited cytotoxicity against A549, HT-29, and P-388 cells with IC $_{50}$ values of 3.5, 1.5 , and $2.6 \mu \mathrm{g} / \mathrm{mL}$, respectively [107]. The other manzamine alkaloids containing one macrocyclic ring are keramamine C (153) [108], acanthomanzamine C (154) [93], kepulauamine A (155) [104], acantholactam (156) [94], and acantholactone (157) [109] (Figure 14). Compound 153 was isolated from the Okinawan marine sponge Amphimedon sp. [108] and was probably a biogenetic precursor of 152. Compound 154 was isolated from $A$. ingens [93] and was recorded as one of the first examples of a manzamine-related alkaloid containing a tetrahydroisoquinoline ring system rather than a $\beta$-carboline moiety. The hexahydrocyclopenta [b]-pyrrol-4(2H)-one ring in $\mathbf{1 5 4}$ could have originated from an eight-membered ring in manzamine A (97). Compound 155 was isolated from an Indonesian marine sponge, Acanthostrongylophora sp. This compound contains a pyrrolizine ring system, which is unique among the manzamines. It exhibited weak inhibition against K562 (human erythroleukemic) and A549 cells and is moderately active against diverse strains of pathogenic bacteria. However, this compound is inactive against sortase A (SrtA) and $\mathrm{Na}^{+} / \mathrm{K}^{+}$-ATPase [104]. Compound 156 was isolated from $A$. ingens and contains a $\gamma$-lactam ring with a $2 Z$-hexenoic acid substituent on the nitrogen atom and is proposed to be biosynthetically derived from compound 97. It shows no proteasome inhibitory activity [94].

Acantholactone (157), a manzamine-related scaffold with unique $\delta$-lactone and $\varepsilon$-lactam rings, was reported from Acanthostrongylophora sp. The absolute configurations of the stereogenic carbons of 157 were determined as $12 S, 24 R, 25 R$, and $26 R$ by comparison of calculated and experimental electronic circular dichroism (ECD) spectra [109].

32,33-Dihydro-31-hydroxymanzamine A (158), 32,33-dihydro-6-hydroxymanzamine A-35-one (159), and 32,33-dihydro-6,31-dihydroxymanzamine A (160) were isolated from an unidentified Indonesian sponge [110]. Compounds 158 and 159 showed no effect against malaria and leishmanial [110]. Rao et al. reported that the decrease of antimalarial activity is attributed to the reduction of the C32-C33 double bond and oxidation of C31 [110].

Manzamine X (161) was reported from Xestospongia sp. Compound 161 exhibited cytotoxic activity against $\mathrm{KB}$ cells, with an $\mathrm{IC}_{50}$ value of $7.9 \mu \mathrm{g} / \mathrm{mL}$ [111].

6-Deoxymanzamine X (162) was isolated from Xestospongia ashmorica [92]. Compound 162 showed cytotoxicity against the L5178 cells with $\mathrm{ED}_{50}$ value of $1.8 \mu \mathrm{g} / \mathrm{mL}$, and exhibited a growth-inhibitory effect against Spodoptera littoralis larvae with a percentage of lethality of $18.8 \%$ at a dose of $132 \mathrm{ppm}$ [92].

Manadomanzamines A (163) and B (164) were reported from the Indonesian sponge, Acanthostrongylophora sp. [112]. These compounds exhibited tubercular effect against Mycobacterium tuberculosis, with MIC values of 1.9 and $1.5 \mu \mathrm{g} / \mathrm{mL}$, respectively. Rifampin was used as a control and showed tubercular effect with MIC values of $0.16 \mu \mathrm{g} / \mathrm{mL}$. Compounds 163 and 164 showed cytotoxic activity against HIV-1, with $\mathrm{EC}_{50}$ values of 7.0 and $16.5 \mu \mathrm{g} / \mathrm{mL}$, respectively. Compound 163 was cytotoxic against A-549 and HCT-116 cells, with $\mathrm{IC}_{50}$ values of 2.5 and $5.0 \mu \mathrm{g} / \mathrm{mL}$, respectively, whereas 164 was cytotoxic against HCT-116, with an $\mathrm{IC}_{50}$ value of $5.0 \mu \mathrm{g} / \mathrm{mL}$. Compounds 163 and 164 were not cytotoxic against the normal Vero cell line at a concentration of $4.8 \mu \mathrm{g} / \mathrm{mL}$. Compound 164 exhibited antifungal effect against Cryptococcus neoformans, with MIC value of $3.5 \mu \mathrm{g} / \mathrm{mL}$, whereas 163 exhibited antifungal activity against Candida albicans with MIC value of $20 \mu \mathrm{g} / \mathrm{mL}$ [112]. 

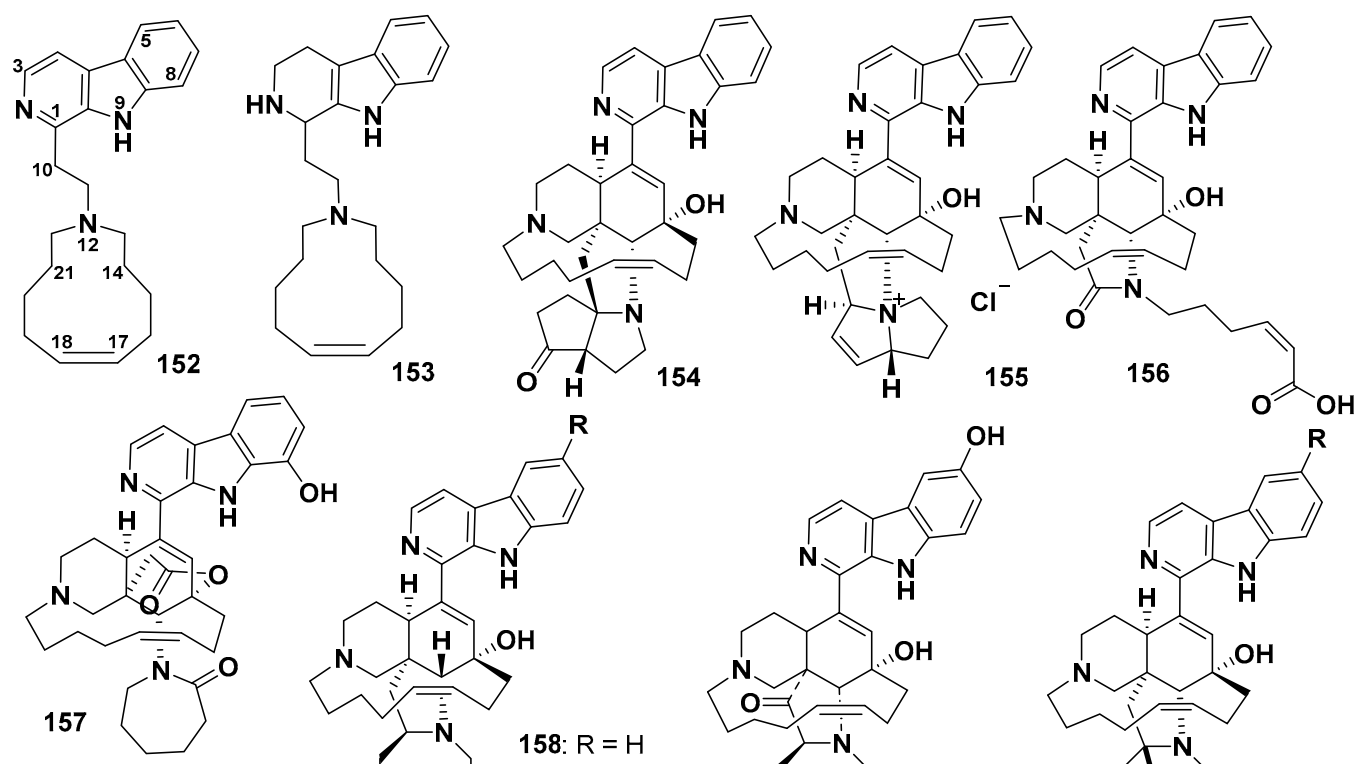

$\mathbf{R}$

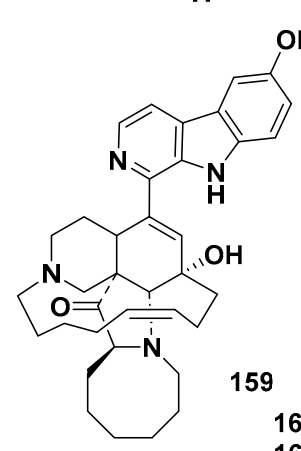

$\mathrm{OH}$<smiles>[R]CC1CCCC1</smiles>

$\mathbf{R}$

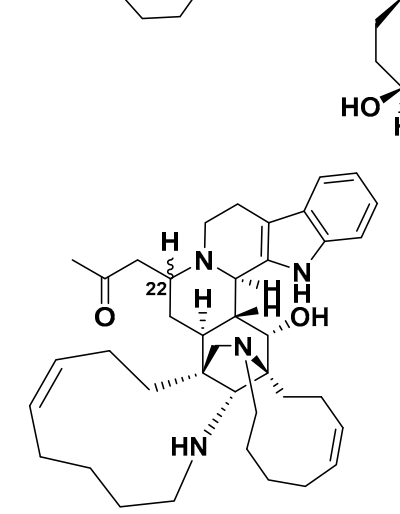

$A$ (163): $22 \beta-H$ and $B(164): 22 \alpha-H$
165

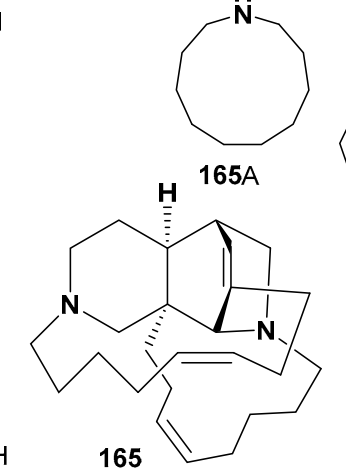

158: $R=H$
160: $R=O H$

H

H

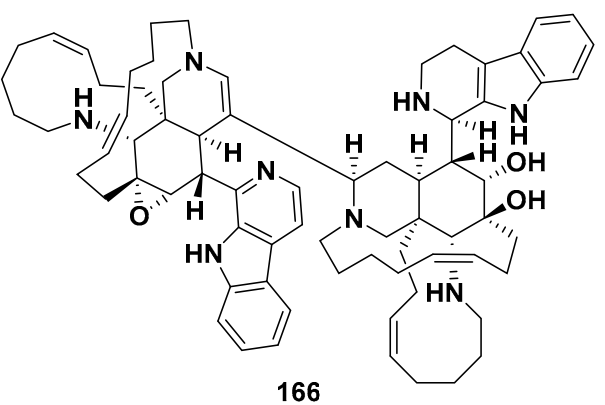

Figure 14. Structures of 152-166.

Keramaphidin B (165), an unprecedented pentacyclic manzamine, was isolated from Amphimedon sp. (Figure 14). Compound 165 exhibited cytotoxic effect against P-388 and KB cells, with $\mathrm{IC}_{50}$ values of 0.28 and $0.3 \mu \mathrm{g} / \mathrm{mL}$, respectively [113].

Kauluamine (166), a manzamine dimer, was isolated from the Indonesian sponge Prianos sp. [114]. Compound 166 exhibited a moderate immunosuppressive effect in a mixed lymphoma reaction [114].

\subsubsection{Structure-Activity Relationship (SAR) of Manzamine Derivatives on Antimalarial Activity}

Manzamines exhibited potent antimalarial activity due to their multifunctionality scaffold. Thus, an overview of the structure-activity relationships (SARs) of manzamines as antimalarial agents can be summarized. The presence of $\beta$-carboline and pentacyclic ring systems played an important role in the antimalarial activities. The absence of these rings, for example in iricinal scaffold, led to decreasing the antimalarial activity. 9- $N$ alkylation of the $\beta$-carboline ring led to decreasing antimalarial activity, whereas 9-NH increased the activity. Hydroxyl group substitution of the $\beta$-carboline ring, particularly position 8 , exhibited no effect as antimalarial. Substitution of the nitro or methoxy groups at position 6 led to slight effects as antimalarial, while it was retained upon substitution of a methyl ester at position 3 of the $\beta$-carboline. The conformational of $\beta$-carboline played a vital role in antimalarial activity of manzamines. Modification of the planarity of $\beta$-carboline by changing pyridine into piperidine and $2-N$-methylation led to reduction of antimalarial activity. An amide substitution on positions 8 and 6 of the $\beta$-carboline ting system reduced antimalarial activity. A 2- $\mathrm{N}$-oxide derivative of manzamine A reserves its antimalarial potency, whereas $2-\mathrm{N}$-methylation of manzamine A decreased antimalarial 
potency against D6 and W2 strains, respectively. The hydroxyl group at C-12 was essential for antimalarial activity. The structure of manzamine $\mathrm{F}$ was connected to the potent antimalarial effect of 8-hydroxymanzamine-A, with a carbonyl group at C-31 and a reduced C-32 double bond, exhibiting a reduction in antimalarial activity. Modification of the $\mathrm{C}-31 \mathrm{C}=\mathrm{O}$ to a hydrazone and alkylation greatly improves the antimalarial effect. Reduction of the carbonyl group at position 31 or introduction of a double bond in conjugation with the carbonyl group (C-31) showed no antimalarial activity. A double bond at carbon-31 in an eight-membered ring was required to maintain the integrity of the ring system and thereby played an important role in contributing to antimalarial activity. Saturation of the double bond at C-31 affects the integrity of the ring and resulting in a significant reduction in antimalarial activity, while a successive reduction of the double bond at C-15 increases antimalarial activity [83].

\subsection{Macrocycles Containing 3-Alkyl Pyridinium Salts}

\subsubsection{Cyclostellettamines}

Cyclostellettamines A-F (167-172) were reported from Stelletta maxima [115] and Pachychalina sp. [8]. Cyclostellettamines G-I (173-175), K (176), and L (177) were isolated from the marine sponge Pachychalina sp. [8] (Figure 15). Compounds 167-177 exhibited antimicrobial activity against Candida albicans ATCC 10231, S. aureus ATCC 25923, Pseudomonas aeruginosa strain P1, E. coli ATCC 25922, P. aeruginosa ATCC 27853 (strain Pa), oxacillin-resistant S. aureus, and oxacillin-resistant S. aureus, whereas 168, 169, 173, and 177 showed potent activity against $M$. tuberculosis H37Rv (MtH37Rv) [116]. Cyclostellettamine C (169) was the most potent antimicrobial activity among all investigated Cyclostellettamines. With the exception of E. coli ATCC 25922 (Ec) and S. aureus ATCC 25923 (Sa), the antimicrobial activity of these cyclostellettamines is suggested to be influenced by the size of the alkyl chains [116]. Dehydrocyclostellettamines D (178), E (179), and cyclostellettamine $\mathrm{G}$ (173) were reported from the sponge of the genus Xestospongia [117]. These compounds showed moderate inhibitory activity against histone deacetylase from $\mathrm{K} 562$ cells with $\mathrm{IC}_{50}$ values of 17,30 , and $80 \mu \mathrm{M}$. Compounds 178, 179, and 173 exhibited cytotoxic activities against P388 cells with $\mathrm{IC}_{50}$ values of $1.3,1.3$, and $2.7 \mu \mathrm{M}$; against HeLa cells with $\mathrm{IC}_{50}$ values of $0.60,1.8$, and $2.8 \mu \mathrm{M}$; and against $3 \mathrm{Y} 1$ (rat fibroblastic cells) $\mathrm{IC}_{50}$ values of $4.3,3.2$, and $11 \mu \mathrm{M}$ [117], respectively. Xu et al. isolated 8,8'-dienecyclostellettamine (180) from the sponge Amphimedon compressa. 180 exhibited strong potent antibacterial activity [118].

Cyclostellettamines N (181), R (182), O (183), and Q (184) were reported from Haliclona viscosa [119]. Eight cyclostellettamine derivatives (185-192) were reported from Haliclona sp., without given specific names [120]. Compounds $\mathbf{1 8 1}$ and 184-192 exhibited moderate cytotoxicity against A549 cancer cell lines, whereas 184, 186, and 190-192 showed strong antibacterial activity against a number of Gram-positive and Gram-negative bacteria [120]. Lee et al. studied the effect of degree of saturation, the length of the alkyl chains, and the double-bond locations effects on the biological activities of the compounds 184, 186, and 190-192, and they found that the biological activities were influenced by (i) the length of the alkyl chains, (ii) the distance between the charged groups, and (iii) the electron-rich locations [120].

In 2017, cyclostellettamine P (193) with C9 and C11 alkyl chains was detected by ion mobility-mass spectrometry [121] (Figure 15). 

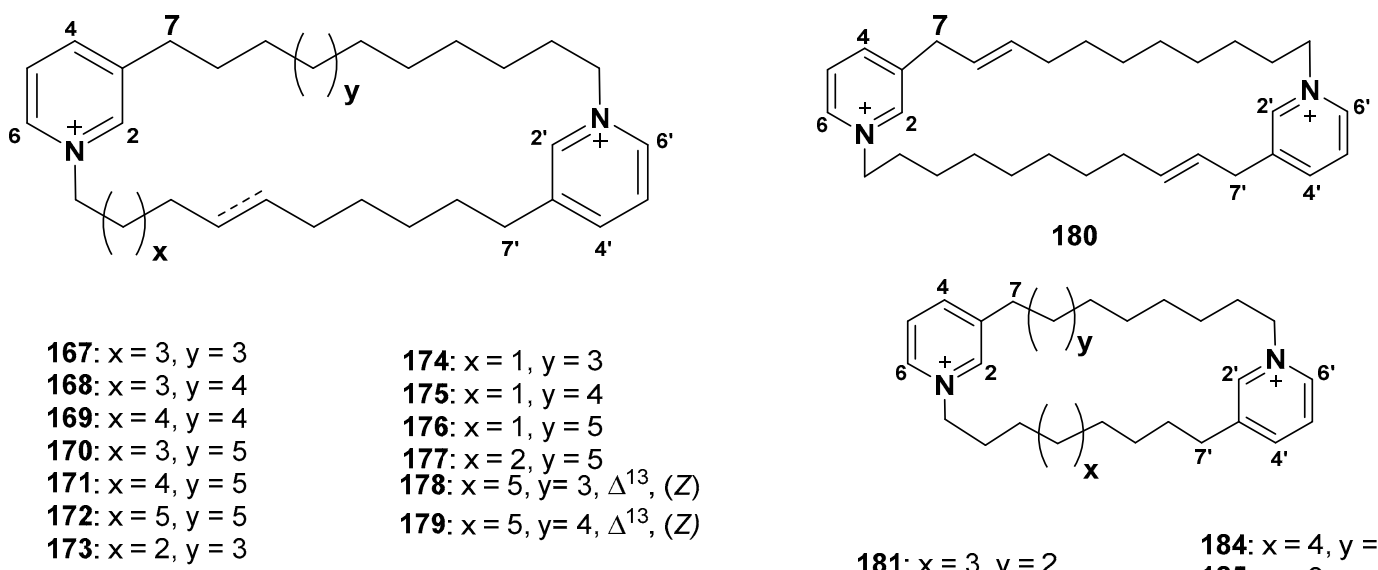

$$
\begin{array}{ll}
\text { 181: } x=3, y=2 & 184: x=4, y=3 \\
\text { 182: } x=4, y=4 & 185: x=3, y=1 \\
183: x=4, y=2 & 186: x=3, y=3 \\
& 193: x=2, y=4
\end{array}
$$<smiles>[Y]C(C)(C)[n+]1cccc(CCCCCCCCCCC[Z7]2cccc(CC/C=C\CCCCCCC)c2)c1</smiles>

187: $x=4, \Delta^{12},(E)$

190: $x=5, \Delta^{15},(Z)$

188: $x=4, \Delta^{13},(Z)$

191: $x=6, \Delta^{13},(Z)$

189: $x=5, \Delta^{9},(Z)$

192: $x=6, \Delta^{15},(Z)$

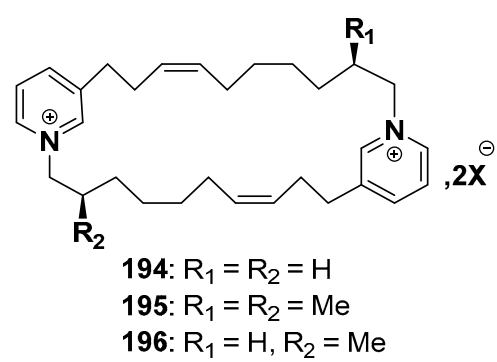

Figure 15. Structures of 167-196.

\subsubsection{Njaoaminiums}

Cyclic 3-alkylpyridinium salts, njaoaminiums A (194), B (195), and C (196) are alkylpyridinium salts (proposed to be the precursor of njaoamine alkaloids) reported from Reniera sp. [122] (Figure 15). Compound 195 exhibited growth inhibitory activity against MDA-MB-231, A549, HT29 with GI 50 values of $4.8,4.1$, and $4.2 \mu \mathrm{M}$ [122].

\subsection{Motuporamines}

Motuporamines A-C (197-199) (Figure 16) [123], were isolated from the marine sponge X. exigua. Later on, three new motuporamines D-F (200-202), a mixture of motuporamines G-I (203-205) (Figure 16) along with compounds 197-199, were isolated from the same marine sponge [124]. This subclass was characterized by the presence of a saturated macrocyclic ring of the 13 to 15 carbons and two basic nitrogen atoms in the linear side chain. Compounds 197-199 and 203-205 exhibited significant anti-invasion effects, with $\mathrm{IC}_{50}$ values less than $15 \mu \mathrm{M}$, whereas no anti-invasion activity was shown by 200 and 201 [124]. The SARs explained the importance of the saturated 15-membered cyclic amine, which fused to the motuporamines diamine side chain, as the required structure for anti-invasive effects [124]. 


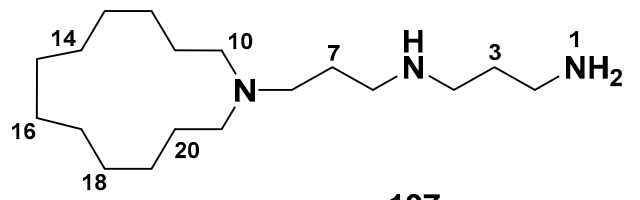

197

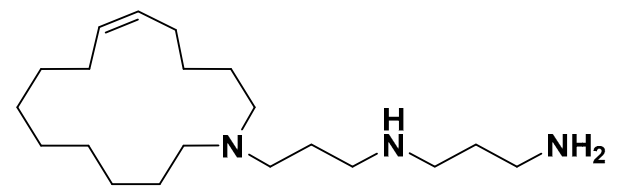

199

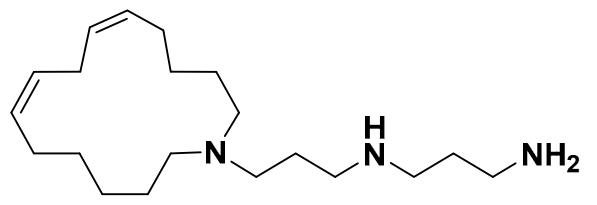

201

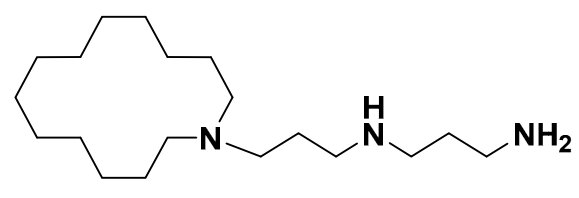

198

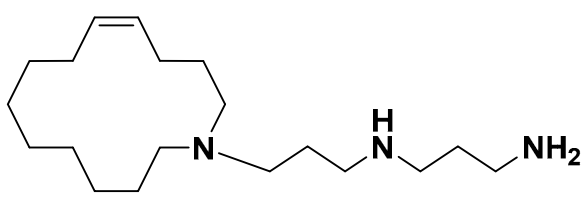

200

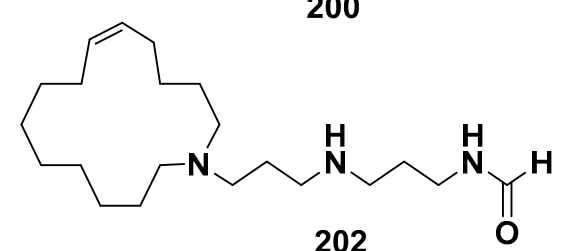<smiles>CCCCCCCCCCN(CCCC)CCCNCCCN</smiles>

203-205

Figure 16. Structures of 197-205.

\section{Biosynthetic Considerations}

Densanin A (1) was a unique alkaloid and was characterized by a hexacyclic diamine skeleton with two long chains. Figure 17 shows a plausible biosynthetic pathway of densanin A from 3-alkylpyridine, as proposed by Baldwin and Whitehead [125].<smiles>C=CC=O</smiles>

Figure 17. Plausible biosynthetic pathway of densanin A.

Cimino et al. proposed that bis-3-alkylpiperidine was the building block of xestospongins, petrosins, and saraines $[40,126]$. They indicated that there was a biosynthetic relationship between the oligomeric halitoxins and the three macrocyclic alkaloids. Another study indicated a detailed hypothetical pathway for the formation of araguspongines, petrosins, and aragupetrosine $\mathrm{A}$ in the marine sponge Xestospongia sp. $[19,126]$. A smart study revealed the relationship between manzarnines and xestospongins, petrosins, and saraines [40]. Baldwin and Whitehead provided the first suggestion about the biogenetic origin of piperidine ring and foresaw the occurrence of ircinal A (121) and B (150) and ingenamine alkaloids (Figure 18) $[39,126]$. Subsequently, three studies indicated the generation 
of the hypothetical pathways to halicyclarnine, saraines $1-3$, saraines $A-C$, and madangarnine skeletons $[39,126]$.

The three basic building blocks of the biosynthesis of 3-alkylpiperidine alkaloids manzamine $\mathrm{C}$ (152), keramaphidin C (165 A), and keramamine C (153) include ammonia, a propenal and a variable chain of saturated or unsaturated linear dialdehyde $[75,127,128]$.

The cross-electrophilic reaction between an equivalent of ammonia with a propenal unit and one terminus of the linear dialdehyde led to a formation of dihydropyridine, with a linear alkyl aldehyde attached at the position 3. Oxidation of the dihydropyridine ring, condensation of the free aldehyde functionality with ammonia, methoxy amine, or simple alkyl amines followed by oxidative or reductive transformations of the resulting imine led directly to monomeric 3-alkylpiperidines [75,85,129].

Chain extension occurred if the aldehyde functionality undertook reductive condensation with ammonia, another equivalent of propenal, and a terminus of another dialdehyde chain to afford a dimer with a second dihydropyridine system. Multiple replications of the elongation sequence were necessary to generate halitoxins. Cyclization involved condensation of the terminal aldehyde functionality at one end of the oligomer and the amino nitrogen in the dihydropyridine ring on the other terminus of the oligomer [129].

Cyclostellettamines result from the oxidation of the dihydropyridine rings containing appropriate linear alkyl bridges, while haliclamines result from reduction of the dihydropyridine rings. Two dialdehydes of 11 carbon atoms were required for the biogenesis of a hypothetical macrocyclic precursor of xestospongins, petrosins, araguspongines, and aragupetrosines. Oxidation of the alkyl chains to afford the diketo-macrocycle intermediate, followed by carbocyclic or heterocyclic ring formation generated either the quinolizidine or the 1-oxaquinolizidine ring systems found in the petrosins, xestospongins, araguspongines, and aragupetrosines [19]. Additionally, transformations including methylation and hydroxylation are common in the biosynthesis of petrosins, xestospongins, and araguspongines [46].

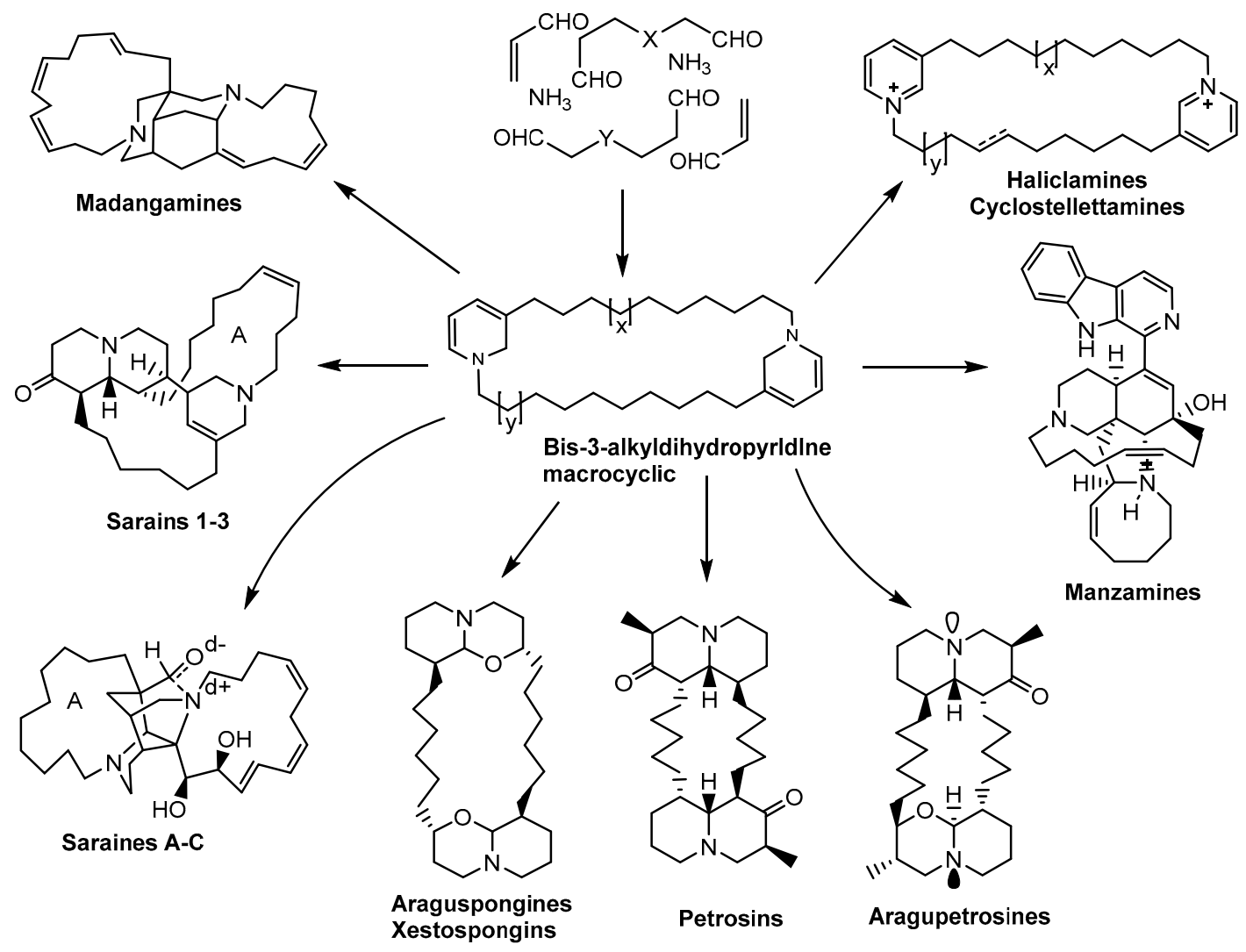

Figure 18. Biosynthetic considerations of the macrocyclic alkaloids originated from 3-alkylpiperidine. 
The pentacyclic skeleton of ingenamine alkaloids arose from a biological intramolecular $[4+2]$ cycloaddition reaction between the tautomeric forms of the two dihydropyridine rings in a bis-3-alkyldihydropyridine macrocycle. The initial [4 +2$]$ adduct intermediate underwent redox exchange to obtain the pentacyclic intermediate. Hydrolysis of the iminium ion functionality led to a tetracyclic seco skeleton with aldehyde functionality. The skeleton and the aldehyde functionality correspond exactly to the skeleton and aldehyde functional group in ircinal A (121). The condensation of the ircinal-type intermediate with tryptamine and oxidation of the resulting product led to manzarnine B (134) (Figure 18).

Ingenamine-type intermediates were suggested as the precursors of halicyclamine A and madangamines. This can be performed through a cleavage of the C-18 and C-33 bond in the ingenarnine-type intermediate, which gives rise to the halicyclamine scaffold [129]. This biogenetic hypothesis was used to assign the relative stereochemistry at C-3 and C-19 in halicyclamine A (77). Cyclization to form a quinolizidine ring system transforms a halicyclamine-type intermediate into the saraine-1 to -3 scaffold [9]. Investigation of saraine A revealed that disconnection of the C2-C3' and C3-Nl' bonds in saraine A (51) generated a halicyclamine scaffold. This confirms that the production of saraine C (53) from saraine A (51) was achieved through a halicyclamine-type intermediate [26,31,128]. Rearrangement of the ingenamine-type intermediate led to the madangamine scaffold $[30,60,128]$. The 3-alkylpiperidine alkaloids were isolated as racemates or unequal mixtures of enantiomers. They were produced by the same biosynthetic manifold but have opposite absolute configurations. Araguspongine $\mathrm{B}$ (31) and petrosins are reported as racemic mixtures, whereas araguspongine $\mathrm{D}(\mathbf{1 7})$ as a 3:7 mixture of (+) and (-) enantiomers, araguspongine $E(19)$ as a 3:2 mixture of $(+)$ and (-) enantiomers, and araguspongines $\mathrm{F}, \mathrm{G}, \mathrm{H}, \mathrm{J}$, and aragupetrosine $\mathrm{A}(\mathbf{2 0})$ as single enantiomers [5]. Araguspongines $\mathrm{F}$ (33), G (34), H (35), and J (36) were obtained as single enantiomers, while the related compounds were obtained as enantiomeric mixtures or meso-compounds; this can be explained by presuming that enantio-selective oxidation or methylation occurs at $\mathrm{C} 9$ or $\mathrm{C} 3$ prior to or after formation of intermediary 1-oxaquinolizidine moieties [46].

A comparison of the absolute configurations of manzamine A (97), manzamine B (134), ircinal A (121), ircinal B (150), ircinol A (120), ircinol B (151), ingenamine (67), ingamine A (65), ingenamine E (71), and keramaphidin B (165) indicated that all of these compounds originated from the same biosynthetic pathway of ingenamine-type intermediate [130]. 97, 121, 134, 150, and one enantiomer of the racemic 165 were categorized in one configuration series. Compounds 65, 67, 71, 120, 151, and another enantiomer of $\mathbf{1 6 5}$ were categorized in another configurational series. The chirality of these alkaloids was established by the biological equivalent of an intramolecular [4 +2 ] cycloaddition reaction of an achiral bis-3-alkyldihydropyridine macrocycle. Therefore, there are enzymes capable of catalyzing this intramolecular condensation [130].

\section{Conclusion and Future Perspective}

This review delivers an inclusive overview of the chemical structures and biological activities of the reported marine-derived macrocyclic alkaloids (MDMAs). There was an incredible increase in the rate of new macrocyclic alkaloids being isolated from marine-derived organisms. Up to 204 macrocyclic alkaloids have been discovered from marine organisms, particularly sponges. These metabolites were categorized under eight subclasses: pyrroles (1\%), quinolines (4\%), bis-quinolizidines (3\%), bis-1-oxaquinolizidines (14\%), 3-alkylpiperidines (25\%), manzamines (34\%), 3-alkyl pyridinium salts $(15 \%)$, and motuporamines $(4 \%)$. The majority of these metabolites were isolated from three genera, Xestospongia, Acanthostrongylophora, and Haliclona. MDMAs displayed potent activities that enabled them to be used as anticancer, anti-invasion, antimalarial, antiplasmodial, and antimicrobial. The reported deep-rooted mode of actions and molecular targets of these compounds were recognized. In this review, the reported structure-activity relationships (SARs) of the marine macrocyclic alkaloids, including the detailed antimalarial SAR of manzamines, were discussed. The multifunctionality of the complex chemical structures provides a wide range of different affinities to receptors. Based on 
the chemical diversity and biological activities of the MDMAs, it is worth studying marine sponges further to find promising lead compounds for the development of marine drugs.

Author Contributions: Conceptualization, W.M.A., H.I.A., and A.A.-L.; methodology, W.M.A., A.A.-L. and H.I.A.; software, H.I.A.; resources, K.O.A.-F. and H.I.A.; writing-original draft preparation, W.M.A., A.A.-L. and H.I.A.; writing-review and editing, W.M.A., A.A.-L., K.O.A.-F. and H.I.A. All authors have read and agreed to the published version of the manuscript.

Funding: This research received no external funding.

Conflicts of Interest: The authors declare no conflict of interest.

\section{References}

1. Nalini, S.; Richard, D.S.; Riyaz, S.M.; Kavitha, G.; Inbakandan, D. Antibacterial macro molecules from marine organisms. Int. J. Biol. Macromol. 2018, 115, 696-710. [CrossRef] [PubMed]

2. Arora, G.; Kulshreshtha, A.; Arora, K.; Talwar, P.; Raj, R.; Grewal, G.; Sajid, A.; Kukreti, R. Emerging themes in drug resistance. In Drug Resistance in Bacteria, Fungi, Malaria, and Cancer; Arora, G., Sajid, A., Kalia, V.C., Eds.; Springer: Cham, Switzerland, 2017; pp. 1-630.

3. Pereira, F.; Aires-de-Sousa, J. Computational methodologies in the exploration of marine natural product leads. Mar. Drugs 2018, 16, 236. [CrossRef] [PubMed]

4. Lakshmi, V.; Srivastava, S.; Mishra, S.K.; Misra, S.; Verma, M.; Misra-Bhattacharya, S. In vitro and in vivo antifilarial potential of marine sponge, Haliclona exigua (Kirkpatrick), against human lymphatic filarial parasite Brugia malayi: Antifilarial activity of H. exigua. Parasitol. Res. 2009, 105, 1295-1301. [CrossRef]

5. Pereira, F. Have marine natural product drug discovery efforts been productive and how can we improve their efficiency? Expert Opin. Drug Discov. 2019, 14, 717-722. [CrossRef] [PubMed]

6. Higa, T.; Tanaka, J.-I.; Tan, L.T. Cytotoxic macrocycles from marine sponges. In New Trends in Natural Product Chemistry, 1st ed.; Rahman, A.-U., Le Quesne, P.W., Eds.; CRC Press: Boca Raton, FL, USA, 1998; pp. 109-120.

7. Rangel, M.; Falkenberg, M. An overview of the marine natural products in clinical trials and on the market. J. Coast. Life Med. 2015, 3, 421-428.

8. De Oliveira, J.H.H.L.; Grube, A.; Köck, M.; Berlinck, R.G.S.; Macedo, M.L.; Ferreira, A.G.; Hajdu, E. Ingenamine $\mathrm{G}$ and cyclostellettamines $\mathrm{G}-\mathrm{I}, \mathrm{K}$, and L from the new Brazilian species of marine sponge Pachychalina sp. J. Nat. Prod. 2004, 67, 1685-1689. [CrossRef]

9. Gafni, J.; Munsch, J.A.; Lam, T.H.; Catlin, M.C.; Costa, L.G.; Molinski, T.F.; Pessah, I.N. Xestospongins: Potent membrane permeable blockers of the inositol 1,4,5-trisphosphate receptor. Neuron 1997, 19, 723-733. [CrossRef]

10. Ang, K.K.H.; Holmes, M.J.; Higa, T.; Hamann, M.T.; Kara, U.A.K. In vivo antimalarial activity of the beta-carboline alkaloid manzamine A. Antimicrob. Agents Chemother. 2000, 44, 1645-1649. [CrossRef]

11. Hwang, B.S.; Oh, J.S.; Jeong, E.J.; Sim, C.J.; Rho, J.-R. Densanins A and B, new macrocyclic pyrrole alkaloids isolated from the marine sponge Haliclona densaspicula. Org. Lett. 2012, 14, 6154-6157. [CrossRef]

12. Bachiller, S.; Jiménez-Ferrer, I.; Paulus, A.; Yang, Y.; Swanberg, M.; Deierborg, T.; Boza-Serrano, A. Microglia in neurological diseases: A road map to brain-disease dependent-inflammatory response. Front. Cell. Neurosci. 2018, 12, 488. [CrossRef]

13. Reyes, F.; Fernandez, R.; Urda, C.; Francesch, A.; Bueno, S.; de Eguilior, C.; Cuevas, C. Njaoamines A-F, new cytotoxic polycyclic alkaloids from the haplosclerid sponge Reniera sp. Tetrahedron 2007, 63, 2432-2438. [CrossRef]

14. Sorek, H.; Rudi, A.; Benayahu, Y.; Kashman, Y. Njaoamines G and H, two new cytotoxic polycyclic alkaloids and a tetrahydroquinolone from the marine sponge Neopetrosia sp. Tetrahedron Lett. 2007, 48, 7691-7694. [CrossRef]

15. Urda, C.; Pérez, M.; Rodríguez, J.; Fernández, R.; Jiménez, C.; Cuevas, C. Njaoamine I, a cytotoxic polycyclic alkaloid from the Haplosclerida sponge Haliclona (Reniera) sp. Tetrahedron Lett. 2018, 59, 2577-2580. [CrossRef]

16. Braekman, J.C.; Daloze, D.; de Abreu, P.M.; Piccinni-Leopardi, C.; Germain, G.; Van Meerssche, M. A novel type of bis-quinolizidine alkaloid from the sponge: Petrosia seriata. Tetrahedron Lett. 1982, 23, 4277-4280. [CrossRef] 
17. Braekman, J.C.; Daloze, D.; Defay, N.; Zimmermann, D. Petrosin-A and-B, two new bis-quinolizidine alkaloids from the sponge Petrosia Seriata. Bull. Soc. Chim. Belg. 1984, 93, 941-944. [CrossRef]

18. Braekman, J.C.; Daloze, D.; Cimino, G.; Trivellone, E. 2D-NMR study of petrosins: Revised structure for petrosin-A. Bull. Soc. Chim. Belg. 1988, 97, 519-524. [CrossRef]

19. Kobayashi, M.; Kawazoe, K.; Kitagawa, I. Aragupetrosine A, a new vasodilative macrocyclic quinolizidine alkaloid from an Okinawan marine sponge Xestospongia sp. Tetrahedron Lett. 1989, 30, 4149-4152. [CrossRef]

20. Dung, D.T.; Hang, D.T.T.; Yen, P.H.; Quang, T.H.; Nhiem, N.X.; Tai, B.H.; Minh, C.V.; Kim, Y.C.; Kim, D.C.; Oh, H.; et al. Macrocyclic bis-quinolizidine alkaloids from Xestospongia muta. Nat. Prod. Res. 2019, 33, 400-406. [CrossRef]

21. Goud, T.V.; Reddy, N.S.; Swamy, N.R.; Ram, T.S.; Venkateswarlu, Y. Anti-HIV active petrosins from the marine sponge Petrosia similis. Biol. Pharm. Bull. 2003, 26, 1498-1501. [CrossRef]

22. Iwagawa, T.; Kaneko, M.; Okamura, H.; Nakatani, M.; van Soest, R.W.; Shiro, M. A new quinolizidine alkaloid from the Papua New Guinean sponge Xestospongia exigua. J. Nat. Prod. 2000, 63, 1310-1311. [CrossRef]

23. Nakagawa, M.; Endo, M.; Tanaka, N.; Lee, G.P. Structures of xestospongin A, B, C and D, novel vasodilative compounds from marine sponge, Xestospongia exigua. Tetrahedron Lett. 1984, 25, 3227-3230. [CrossRef]

24. Singh, K.S.; Das, B.; Naik, C.G. Quinolizidines alkaloids: Petrosin and xestospongins from the sponge Oceanapia sp. J. Chem. Sci. 2011, 123, 601-607. [CrossRef]

25. Moon, S.-S.; MacMillan, J.B.; Olmstead, M.M.; Ta, T.A.; Pessah, I.N.; Molinski, T.F. (+)-7 S-Hydroxyxestospongin A from the marine sponge Xestospongia sp. and absolute configuration of (+)-xestospongin D. J. Nat. Prod. 2002, 65, 249-254. [CrossRef] [PubMed]

26. Quirion, J.-C.; Sevenet, T.; Husson, H.-P.; Weniger, B.; Debitus, C. Two new alkaloids from Xestospongia sp., a new Caledonian sponge. J. Nat. Prod. 1992, 55, 1505-1508. [CrossRef]

27. Reddy, M.V.R.; Faulkner, D.J. 3 $\beta, 3^{\prime} \beta$-Dimethylxestospongin C, a new bis-1-oxaquinolizidine alkaloid from the Palauan sponge Xestospongia sp. Nat. Prod. Lett. 1997, 11, 53-59. [CrossRef]

28. Li, Y.; Qin, S.; Guo, Y.-W.; Gu, Y.-C.; van Soest, R.W. 9'-Epi-3 $\beta, 3^{\prime} \beta$-dimethylxestospongin C, a new macrocyclic diamine alkaloid from the Hainan sponge Neopetrosia exigua. Planta Med. 2011, 77, 179-181. [CrossRef]

29. Kobayashi, M.; Kawazoe, K.; Kitagawa, I. Araguspongines B, C, D, E, F, G, H, and J, new vasodilative bis-1-oxaquinolizidine alkaloids from an Okinawan marine sponge, Xestospongia sp. Chem. Pharm. Bull. 1989, 37, 1676-1678. [CrossRef] [PubMed]

30. Venkateswarlu, Y.; Reddy, M.V.R.; Rao, J.V. bis-1-Oxaquinolizidines from the sponge Haliclona exigua. J. Nat. Prod. 1994, 57, 1283-1285. [CrossRef]

31. Hoye, T.R.; North, J.T.; Yao, L.J. Conformational considerations in 1-oxaquinolizidines related to the xestospongin/araguspongine family: Reassignment of stereostructures for araguspongines B and E. J. Org. Chem. 1994, 59, 6904-6910. [CrossRef]

32. Boerjesson, L.; Csoeregh, I.; Welch, C.J. Synthesis and conformational analysis of 2, 9-disubstituted 1-oxaquinolizidines. J. Org. Chem. 1995, 60, 2989-2999. [CrossRef]

33. Orabi, K.Y.; El Sayed, K.A.; Hamann, M.T.; Dunbar, D.C.; Al-Said, M.S.; Higa, T.; Kelly, M. Araguspongines $\mathrm{K}$ and $\mathrm{L}$, new bioactive bis-1-oxaquinolizidine N-oxide alkaloids from Red Sea specimens of Xestospongia exigua. J. Nat. Prod. 2002, 65, 1782-1785. [CrossRef] [PubMed]

34. Liu, H.; Mishima, Y.; Fujiwara, T.; Nagai, H.; Kitazawa, A.; Mine, Y.; Kobayashi, H.; Yao, X.; Yamada, J.; Oda, T. Isolation of araguspongine $\mathrm{M}$, a new stereoisomer of an araguspongine/xestospongin alkaloid, and dopamine from the marine sponge Neopetrosia exigua collected in Palau. Mar. Drugs 2004, 2, 154-163. [CrossRef]

35. Tanaka, J.; Higa, T.; Garcia, G.; Ruffles, G. bis-1-Oxaquinolizidine alkaloids from a marine sponge with antitumor activity. WO 97/04783. 13 February 1997.

36. Mol, V.L.; Raveendran, T.; Parameswaran, P. Antifouling activity exhibited by secondary metabolites of the marine sponge, Haliclona exigua (Kirkpatrick). Int. Biodeterior. Biodegradation. 2009, 63, 67-72.

37. Akl, M.R.; Ayoub, N.M.; Ebrahim, H.Y.; Mohyeldin, M.M.; Orabi, K.Y.; Foudah, A.I.; Sayed, K.A.E. Araguspongine $\mathrm{C}$ induces autophagic death in breast cancer cells through suppression of c-Met and HER2 receptor tyrosine kinase signaling. Mar. Drugs 2015, 13, 288-311. [CrossRef] 
38. Jaimovich, E.; Mattei, C.; Liberona, J.L.; Cardenas, C.; Estrada, M.; Barbier, J.; Debitus, C.; Laurent, D.; Molgó, J. Xestospongin B, a competitive inhibitor of IP3-mediated $\mathrm{Ca}^{2+}$ signalling in cultured rat myotubes, isolated myonuclei, and neuroblastoma (NG108-15) cells. FEBS Lett. 2005, 579, 2051-2057. [CrossRef] [PubMed]

39. Cimino, G.; Stefano, S.D.; Scognamiglio, G.; Sodano, G.; Trivellone, E. Sarains: A new class of alkaloids from the marine sponge Reniera sarai. Bull. Soc. Chim. Belg. 1986, 95, 783-800. [CrossRef]

40. Cimino, G.; Spinella, A.; Trivellone, E. Isosarain-1: A new alkaloid from the Mediterranean sponge Reniera sarai. Tetrahedron Lett. 1989, 30, 133-136. [CrossRef]

41. Guo, Y.; Trivellone, E.; Scognamiglio, G.; Cimino, G. Absolute stereochemistry of isosaraine-1 and isosaraine-2. Tetrahedron Lett. 1998, 39, 463-466. [CrossRef]

42. Guo, Y.; Madaio, A.; Trivellone, E.; Scognamiglio, G.; Cimino, G. Further studies of alkaloids from Reniera sarai: Structures of saraine-3 and isosaraine-3; Absolute stereochemistry of saraine- 1 and saraine-2. Tetrahedron 1996, 52, 14961-14974. [CrossRef]

43. Guo, Y.; Madaio, A.; Trivellone, E.; Scognamiglio, G.; Cimino, G. Structural and stereochemical studies of saraines: Macrocyclic alkaloids of the sponge Reniera sarai. Tetrahedron 1996, 52, 8341-8348. [CrossRef]

44. Cimino, G.; Scognamiglio, G.; Spinella, A.; Trivellone, E. Structural studies on saraine A. J. Nat. Prod. 1990, 53, 1519-1525. [CrossRef]

45. Caprioli, V.; Cimino, G.; De, A.G.; Madaio, A.; Scognamiglio, G.; Trivellone, E. Selected biological activities of saraines. Comp. Biochem. Physiol. B 1992, 103, 293-296. [CrossRef]

46. Kong, F.; Andersen, R.J.; Allen, T.M. Madangamine A, a novel cytotoxic alkaloid from the marine sponge Xestospongia ingens. J. Am. Chem. Soc. 1994, 116, 6007-6008. [CrossRef]

47. Kong, F.; Graziani, E.I.; Andersen, R.J. Madangamines B-E, pentacyclic alkaloids from the marine sponge Xestospongia ingens. J. Nat. Prod. 1998, 61, 267-271. [CrossRef]

48. De Oliveira, J.; Nascimento, A.M.; Kossuga, M.H.; Cavalcanti, B.C.; Pessoa, C.O.; Moraes, M.O.; Macedo, M.L.; Ferreira, A.G.; Hajdu, E.; Pinheiro, U.S.; et al. Cytotoxic alkylpiperidine alkaloids from the Brazilian marine sponge Pachychalina alcaloidifera. J. Nat. Prod. 2007, 70, 538-543. [CrossRef]

49. Amat, M.; Pérez, M.; Ballette, R.; Proto, S.; Bosch, J. The alkaloids of the madangamine group. In The Alkaloids; Knölker, H.-J., Ed.; Elsevier: Oxford, UK, 2015; Volume 74, pp. 159-199.

50. Abdjul, D.B.; Yamazaki, H.; Kanno, S.; Takahashi, O.; Kirikoshi, R.; Ukai, K.; Namikoshi, M. Haliclonadiamine derivatives and 6-epi-monanchorin from the marine sponge Halichondria panicea collected at Iriomote Island. J. Nat. Prod. 2016, 79, 1149-1154. [CrossRef]

51. Baker, B.J.; Scheuer, P.J.; Shoolery, J.N. Papuamine, an antifungal pentacyclic alkaloid from a marine sponge, Haliclona sp. J. Am. Chem. Soc. 1988, 110, 965-966. [CrossRef]

52. Fahy, E.; Molinski, T.F.; Harper, M.K.; Sullivan, B.W.; Faulkner, D.J.; Parkanyi, L.; Clardy, J. Haliclonadiamine, an antimicrobial alkaloid from the sponge Haliclona sp. Tetrahedron Lett. 1988, 29, 3427-3428. [CrossRef]

53. Hou, X.M.; Wang, C.Y.; Gerwick, W.H.; Shao, C.L. Marine natural products as potential anti-tubercular agents. Eur. J. Med. Chem. 2019, 165, 273-292. [CrossRef] [PubMed]

54. Liu, H.-B.; Imler, G.H.; Baldridge, K.K.; O'Connor, R.D.; Siegel, J.S.; Deschamps, J.R.; Bewley, C.A. X-ray crystallography and unexpected chiroptical properties reassign the configuration of haliclonadiamine. J. Am. Chem. Soc. 2020, 142, 2755-2759. [CrossRef]

55. Kong, F.; Andersen, R.J.; Allen, T.M. Ingamines A and B, new cytotoxic alkaloids from the marine sponge Xestospongia ingens. Tetrahedron 1994, 50, 6137-6144. [CrossRef]

56. Kong, F.; Andersen, R.J.; Allen, T.M. Ingenamine, a novel pentacyclic alkaloid from the marine sponge Xestospongia ingens. Tetrahedron Lett. 1994, 35, 1643-1646. [CrossRef]

57. Kong, F.; Andersen, R.J. Ingenamine alkaloids isolated from the sponge Xestospongia ingens: Structures and absolute configurations. Tetrahedron 1995, 51, 2895-2906. [CrossRef]

58. Ilias, M.; Ibrahim, M.A.; Khan, S.I.; Jacob, M.R.; Tekwani, B.L.; Walker, L.A.; Samoylenko, V. Pentacyclic ingamine alkaloids, a new antiplasmodial pharmacophore from the marine sponge Petrosid Ng5 Sp5. Planta Med. 2012, 78, 1690-1697. [CrossRef]

59. Rodriguez, J.; Peters, B.M.; Kurz, L.; Schatzman, R.C.; McCarley, D.; Lou, L.; Crews, P. An alkaloid protein kinase $\mathrm{C}$ inhibitor, xestocyclamine A, from the marine sponge Xestospongia sp. J. Am. Chem. Soc. 1993, 115, 10436-10437. [CrossRef] 
60. Jaspars, M.; Pasupathy, V.; Crews, P. A tetracyclic diamine alkaloid, halicyclamine A, from the marine sponge Haliclona sp. J. Org. Chem. 1994, 59, 3253-3255. [CrossRef]

61. Harrison, B.; Talapatra, S.; Lobkovsky, E.; Clardy, J.; Crews, P. The structure and biogenetic origin of (-) halicyclamine B from a Xestospongia sponge. Tetrahedron Lett. 1996, 37, 9151-9154. [CrossRef]

62. Charan, R.D.; Garson, M.J.; Brereton, I.M.; Willis, A.C.; Hooper, J.N. Haliclonacyclamines A and B, cytotoxic alkaloids from the tropical marine sponge Haliclona sp. Tetrahedron 1996, 52, 9111-9120. [CrossRef]

63. Arai, M.; Ishida, S.; Setiawan, A.; Kobayashi, M. Haliclonacyclamines, tetracyclic alkylpiperidine alkaloids, as anti-dormant mycobacterial substances from a marine sponge of Haliclona sp. Chem. Pharm. Bull. 2009, 57, 1136-1138. [CrossRef] [PubMed]

64. Mudianta, I.W.; Katavic, P.L.; Lambert, L.K.; Hayes, P.Y.; Banwell, M.G.; Munro, M.H.; Bernhardt, P.V.; Garson, M.J. Structure and absolute configuration of 3-alkylpiperidine alkaloids from an Indonesian sponge of the genus Halichondria. Tetrahedron 2010, 66, 2752-2760. [CrossRef]

65. Arai, M.; Liu, L.; Fujimoto, T.; Setiawan, A.; Kobayashi, M. DedA protein relates to action-mechanism of halicyclamine A, a marine spongean macrocyclic alkaloid, as an anti-dormant mycobacterial substance. Mar. Drugs 2011, 9, 984-993. [CrossRef] [PubMed]

66. Mani, L.; Petek, S.; Valentin, A.; Chevalley, S.; Folcher, E.; Aalbersberg, W.; Debitus, C. The in vivo anti-plasmodial activity of haliclonacyclamine A, an alkaloid from the marine sponge, Haliclona sp. Nat. Prod. Res. 2011, 25, 1923-1930. [CrossRef] [PubMed]

67. Clark, R.J.; Field, K.L.; Charan, R.D.; Garson, M.J.; Brereton, M.; Willis, A.C. The haliclonacyclamines, cytotoxic tertiary alkaloids from the tropical marine sponge Haliclona sp. Tetrahedron 1998, 54, 8811-8826. [CrossRef]

68. Torres, Y.R.; Berlinck, R.G.; Magalhães, A.; Schefer, A.B.; Ferreira, A.G.; Hajdu, E.; Muricy, G. Arenosclerins A-C and haliclonacyclamine E, new tetracyclic alkaloids from a Brazilian endemic Haplosclerid sponge Arenosclerab rasiliensis. J. Nat. Prod. 2000, 63, 1098-1105. [CrossRef]

69. Torres, Y.R.; Berlinck, R.G.; Nascimento, G.G.; Fortier, S.C.; Pessoa, C.; de Moraes, M.O. Antibacterial activity against resistant bacteria and cytotoxicity of four alkaloid toxins isolated from the marine sponge Arenosclera brasiliensis. Toxicon 2002, 40, 885-891. [CrossRef]

70. Chill, L.; Yosief, T.; Kashman, Y. Halichondramine, a new tetracyclic bipiperidine alkaloid from the marine sponge Halichondria sp. J. Nat. Prod. 2002, 65, 1738-1741. [CrossRef]

71. Wei, X.; Nieves, K.; Rodríguez, A.D. Neopetrosiamine A, biologically active bis-piperidine alkaloid from the Caribbean Sea sponge Neopetrosia proxima. Bioorg. Med. Chem. Lett. 2010, 20, 5905-5908. [CrossRef]

72. Kato, H.; El-Desoky, A.H.; Takeishi, Y.; Nehira, T.; Angkouw, E.D.; Mangindaan, R.E.P.; de Voogd, N.J.; Tsukamoto, S. Tetradehydrohalicyclamine B, a new proteasome inhibitor from the marine sponge Acanthostrongylophora ingens. Bioorg. Med. Chem. Lett. 2019, 29, 8-10. [CrossRef]

73. Rodriguez, J. Bioactive natural products (part E); polycyclic amine alkaloids (3-alkylpiperidine alkaloids), novel narine bioactive compounds: Structure, synthesis and biochemical aspects. In Studies in Natural Products Chemistry, 1st ed.; Atta-ur-Rahman, Ed.; Elsevier Science, B.V.: Amsterdam, The Netherlands, 2000; Volume 24, pp. 573-681.

74. Peng, J.; Rao, K.V.; Choo, Y.M.; Hamann, M.T. Manzamine alkaloids. In Modern Alkaloids: Structure, Isolation, Synthesis, and Biology; Fattorusso, E., Taglialatela-Scafati, O., Eds.; WILEY-VCH Verlag GmbH \& Co.: Weinheim, Germany, 2008; pp. 189-232.

75. Sakai, R.; Higa, T.; Jefford, C.W.; Bernardinelli, G. Manzamine A, a novel antitumor alkaloid from a sponge. J. Am. Chem. Soc. 1986, 108, 6404-6405. [CrossRef]

76. Nakamura, H.; Deng, S.; Kobayashi, J.i.; Ohizumi, Y.; Tomotake, Y.; Matsuzaki, T.; Hirata, Y. Keramamine-A and-B, novel antimicrobial alkaloids from the Okinawan marine sponge Pellina sp. Tetrahedron Lett. 1987, 28, 621-624. [CrossRef]

77. Rao, K.V.; Kasanah, N.; Wahyuono, S.; Tekwani, B.L.; Schinazi, R.F.; Hamann, M.T. Three new manzamine alkaloids from a common Indonesian sponge and their activity against infectious and tropical parasitic diseases. J. Nat. Prod. 2004, 67, 1314-1318. [CrossRef] [PubMed]

78. Kallifatidis, G.; Hoepfner, D.; Jaeg, T.; Guzman, E.A.; Wright, A.E. The marine natural product manzamine A targets vacuolar ATPases and inhibits autophagy in pancreatic cancer cells. Mar. Drugs 2013, 11, 3500-3516. [CrossRef] 
79. Lin, L.C.; Kuo, T.T.; Chang, H.Y.; Liu, W.S.; Hsia, S.M.; Huang, T.C. Manzamine A exerts anticancer activity against human colorectal cancer cells. Mar. Drugs 2018, 16, 252. [CrossRef]

80. Hamann, M.; Alonso, D.; Martín-Aparicio, E.; Fuertes, A.; Pérez-Puerto, M.J.; Castro, A.; Morales, S.; Navarro, M.L.; del Monte-Millán, M.; Medina, M. Glycogen synthase kinase-3 (GSK-3) inhibitory activity and structure-Activity relationship (SAR) studies of the manzamine alkaloids. potential for Alzheimer's disease. J. Nat. Prod. 2007, 70, 1397-1405. [CrossRef] [PubMed]

81. Palem, J.R.; Mudit, M.; Hsia, S.V.; Sayed, K.A. Discovery and preliminary structure-activity relationship of the marine natural product manzamines as herpes simplex virus type-1 inhibitors. Z. Nat. C 2017, 72, 49-54. [CrossRef] [PubMed]

82. Ichiba, T.; Corgiat, J.M.; Scheuer, P.J.; Kelly-Borges, M. 8-Hydroxymanzamine A, a $\beta$-carboline alkaloid from a sponge, Pachypellina sp. J. Nat. Prod. 1994, 57, 168-170. [CrossRef]

83. Ashok, P.; Ganguly, S.; Murugesan, S. Manzamine alkaloids: Isolation, cytotoxicity, antimalarial activity and SAR studies. Drug Discov. Today 2014, 19, 1781-1791. [CrossRef]

84. Kobayashi, J.i.; Tsuda, M.; Kawasaki, N.; Sasaki, T.; Mikami, Y. 6-Hydroxymanzamine A and 3, 4-dihydromanzamine A, new alkaloids from the Okinawan marine sponge Amphimedon sp. J. Nat. Prod. 1994, 57, 1737-1740. [CrossRef]

85. Crews, P.; Cheng, X.-C.; Adamczeski, M.; Rodríguez, J.; Jaspars, M.; Schmitz, F.J.; Traeger, S.C.; Pordesimo, E.O. 1,2,3,4-Tetrahydro-8-hydroxymanzamines, alkaloids from two different haplosclerid sponges. Tetrahedron 1994, 50, 13567-13574. [CrossRef]

86. Kondo, K.; Shigemori, H.; Kikuchi, Y.; Ishibashi, M.; Sasaki, T.; Kobayashi, J. Ircinals A and B from the Okinawan marine sponge Ircinia sp.: Plausible biogenetic precursors of manzamine alkaloids. J. Org. Chem. 1992, 57, 2480-2483. [CrossRef]

87. Watanabe, D.; Tsuda, M.; Kobayashi, J.i. Three new manzamine congeners from Amphimedon sponge. J. Nat. Prod. 1998, 61, 689-692. [CrossRef] [PubMed]

88. Zhou, B.-N.; Slebodnick, C.; Johnson, R.K.; Mattern, M.R.; Kingston, D.G. New cytotoxic manzamine alkaloids from a Palaun sponge. Tetrahedron 2000, 56, 5781-5784. [CrossRef]

89. Yousaf, M.; El Sayed, K.A.; Rao, K.V.; Lim, C.W.; Hu, J.-F.; Kelly, M.; Franzblau, S.G.; Zhang, F.; Peraud, O.; Hill, R.T. 12,34-Oxamanzamines, novel biocatalytic and natural products from manzamine producing Indo-Pacific sponges. Tetrahedron 2002, 58, 7397-7402. [CrossRef]

90. El Sayed, K.; Kelly, M.; Kara, U.; Ang, K.; Katsuyama, I.; Dunbar, D.; Khan, A.; Hamann, M. New manzamine alkaloids with potent activity against infectious diseases. J. Am. Chem. Soc. 2001, 123, 1804-1808. [CrossRef] [PubMed]

91. Yousaf, M.; Hammond, N.L.; Peng, J.; Wahyuono, S.; McIntosh, K.A.; Charman, W.N.; Mayer, A.M.; Hamann, M.T. New manzamine alkaloids from an Indo-Pacific sponge. Pharmacokinetics, oral availability, and the significant activity of several manzamines against HIV-I, AIDS opportunistic infections, and inflammatory diseases. J. Med. Chem. 2004, 47, 3512-3517. [CrossRef] [PubMed]

92. Edrada, R.A.; Proksch, P.; Wray, V.; Witte, L.; Müller, W.; Van Soest, R.W. Four new bioactive manzamine-type alkaloids from the Philippine marine sponge Xestospongia ashmorica. J. Nat. Prod. 1996, 59, 1056-1060. [CrossRef]

93. Furusato, A.; Kato, H.; Nehira, T.; Eguchi, K.; Kawabata, T.; Fujiwara, Y.; Losung, F.; Mangindaan, R.E.; de Voogd, N.J.; Takeya, M. Acanthomanzamines A-E with new manzamine frameworks from the marine sponge Acanthostrongylophora ingens. Org. Lett. 2014, 16, 3888-3891. [CrossRef]

94. El-Desoky, A.H.; Kato, H.; Eguchi, K.; Kawabata, T.; Fujiwara, Y.; Losung, F.; Mangindaan, R.E.; de Voogd, N.J.; Takeya, M.; Yokosawa, H.; et al. Acantholactam and pre-neo-kauluamine, manzamine-related alkaloids from the Indonesian marine sponge Acanthostrongylophora ingens. J. Nat. Prod. 2014, 77, 1536-1540. [CrossRef]

95. Yamada, M.; Takahashi, Y.; Kubota, T.; Fromont, J.; Ishiyama, A.; Otoguro, K.; Yamada, H.; Ōmura, S.; Kobayashi, J. Zamamidine C, 3,4-dihydro-6-hydroxy-10,11-epoxymanzamine A, and 3,4-dihydromanzamine J N-oxide, new manzamine alkaloids from sponge Amphimedon sp. Tetrahedron 2009, 65, 2313-2317. [CrossRef]

96. Kubota, T.; Nakamura, K.; Kurimoto, S.I.; Sakai, K.; Fromont, J.; Gonoi, T.; Kobayashi, J. Zamamidine D, a manzamine alkaloid from an Okinawan Amphimedon sp. marine sponge. J. Nat. Prod. 2017, 80, 1196-1199. [CrossRef]

97. Kobayashi, J.; Watanabe, D.; Kawasaki, N.; Tsuda, M. Nakadomarin A, a novel hexacyclic manzamine-related alkaloid from Amphimedon sponge. J. Org. Chem. 1997, 62, 9236-9239. [CrossRef] 
98. Tsuda, M.; Kawasaki, N.; Kobayashi, J. Ircinols A and B, first antipodes of manzamine-related alkaloids from an Okinawan marine sponge. Tetrahedron 1994, 50, 7957-7960. [CrossRef]

99. AlTarabeen, M.; Daletos, G.; Ebrahim, W.; Müller, W.E.; Hartmann, R.; Lin, W.; Proksch, P. Ircinal E, a new manzamine derivative from the Indonesian marine sponge Acanthostrongylophora ingens. Nat. Prod. Commun. 2015, 10, 1951-1953. [CrossRef]

100. Rao, K.V.; Donia, M.S.; Peng, J.; Garcia-Palomero, E.; Alonso, D.; Martinez, A.; Medina, M.; Franzblau, S.G.; Tekwani, B.L.; Khan, S.I. Manzamine B and E and ircinal A related alkaloids from an Indonesian Acanthostrongylophora sponge and their activity against infectious, tropical parasitic, and Alzheimer's diseases. J. Nat. Prod. 2006, 69, 1034-1040. [CrossRef]

101. Ichiba, T.; Sakai, R.; Kohmoto, S.; Saucy, G.; Higa, T. New manzamine alkaloids from a sponge of the genus Xestospongia. Tetrahedron Lett. 1988, 29, 3083-3086. [CrossRef]

102. Sakai, R.; Kohmoto, S.; Higa, T.; Jefford, C.W.; Bernardinelli, G. Manzamine B and C, two novel alkaloids from the sponge Haliclona sp. Tetrahedron Lett. 1987, 28, 5493-5496. [CrossRef]

103. Tsuda, M.; Inaba, K.; Kawasaki, N.; Honma, K.; Kobayashi, J.i. Chiral resolution of ( \pm )-keramaphidin B and isolation of manzamine $\mathrm{L}$, a new $\beta$-carboline alkaloid from a sponge Amphimedon sp. Tetrahedron 1996, 52, 2319-2324. [CrossRef]

104. Kim, C.K.; Riswanto, R.; Won, T.H.; Kim, H.; Elya, B.; Sim, C.J.; Oh, D.C.; Oh, K.B.; Shin, J. Manzamine alkaloids from an Acanthostrongylophora sp. sponge. J. Nat. Prod. 2017, 80, 1575-1583. [CrossRef]

105. Tsuda, M.; Watanabe, D.; Kobayashi, J. Ma'eganedin A, a new manzamine alkaloid from Amphimedon sponge. Tetrahedron Lett. 1998, 39, 1207-1210. [CrossRef]

106. Takahashi, Y.; Kubota, T.; Fromont, J.; Kobayashi, J.i. Zamamidines A and B, new manzamine alkaloids from the sponge Amphimedon species. Org. Lett. 2008, 11, 21-24. [CrossRef]

107. Longley, R.E.; McConnell, O.J.; Essich, E.; Harmody, D. Evaluation of marine sponge metabolites for cytotoxicity and signal transduction activity. J. Nat. Prod. 1993, 56, 915-920. [CrossRef]

108. Tsuda, M.; Kawasaki, N.; Kobayashi, J.i. Keramaphidin C and keramamine C plausible biogenetic precursors of manzamine C from an Okinawan marine sponge. Tetrahedron Lett. 1994, 35, 4387-4388. [CrossRef]

109. Wahba, A.E.; Fromentin, Y.; Zou, Y.; Hamann, M.T. Acantholactone, a new manzamine related alkaloid with an unprecedented delta-lactone and epsilon-lactam ring system. Tetrahedron Lett. 2012, 53, 6329-6331. [CrossRef] [PubMed]

110. Rao, K.V.; Santarsiero, B.D.; Mesecar, A.D.; Schinazi, R.F.; Tekwani, B.L.; Hamann, M.T. New manzamine alkaloids with activity against infectious and tropical parasitic diseases from an Indonesian sponge. J. Nat. Prod. 2003, 66, 823-828. [CrossRef]

111. Kobayashi, M.; Chen, Y.-J.; Aoki, S.; In, Y.; Ishida, T.; Kitagawa, I. Four new $\beta$-carboline alkaloids isolated from two Okinawan marine sponges of Xestospongia sp. and Haliclona sp. Tetrahedron 1995, 51, 3727-3736. [CrossRef]

112. Peng, J.; Hu, J.-F.; Kazi, A.B.; Li, Z.; Avery, M.; Peraud, O.; Hill, R.T.; Franzblau, S.G.; Zhang, F.; Schinazi, R.F. Manadomanzamines A and B: A novel alkaloid ring system with potent activity against mycobacteria and HIV-1. J. Am. Chem. Soc. 2003, 125, 13382-13386. [CrossRef]

113. Kobayashi, J.i.; Tsuda, M.; Kawasaki, N.; Matsumoto, K.; Adachi, T. Keramaphidin B, a novel pentacyclic alkaloid from a marine sponge Amphimedon sp.: A plausible biogenetic precursor of manzamine alkaloids. Tetrahedron Lett. 1994, 35, 4383-4386. [CrossRef]

114. Ohtani, I.I.; Ichiba, T.; Isobe, M.; Kelly-Borges, M.; Scheuer, P.J. Kauluamine, an unprecedented manzamine dimer from an Indonesian marine sponge, Prianos sp. J. Am. Chem. Soc. 1995, 117, 10743-10744. [CrossRef]

115. Fusetani, N.; Asai, N.; Matsunaga, S.; Honda, K.; Yasumuro, K. Cyclostellettamines AF, pyridine alkaloids which inhibit binding of methyl quinuclidinyl benzilate (QNB) to muscarinic acetylcholine receptors, from the marine sponge, Stelletta maxima. Tetrahedron Lett. 1994, 35, 3967-3970. [CrossRef]

116. De Oliveira, J.; Seleghim, M.; Timm, C.; Grube, A.; Köck, M.; Nascimento, G.; Martins, A.; Silva, E.; De Souza, A.; Minarini, P. Antimicrobial and antimycobacterial activity of cyclostellettamine alkaloids from sponge Pachychalina sp. Mar. Drugs 2006, 4, 1-8. [CrossRef]

117. Oku, N.; Nagai, K.; Shindoh, N.; Terada, Y.; van Soest, R.W.; Matsunaga, S.; Fusetani, N. Three new cyclostellettamines, which inhibit histone deacetylase, from a marine sponge of the genus Xestospongia. Bioorg. Med. Chem. Lett. 2004, 14, 2617-2620. [CrossRef] [PubMed] 
118. Xu, N.J.; Sun, X.; Yan, X.J. A new cyclostellettamine from sponge Amphimedon compressa. Chin. Chem. Lett. 2007, 18, 947-950. [CrossRef]

119. Schmidt, G.; Timm, C.; Köck, M. New haliclamines E and F from the Arctic sponge Haliclona viscosa. Org. Biomol. Chem. 2009, 7, 3061-3064. [CrossRef]

120. Lee, Y.; Jang, K.H.; Jeon, J.; Yang, W.-Y.; Sim, C.J.; Oh, K.-B.; Shin, J. Cyclic bis-1,3-dialkylpyridiniums from the sponge Haliclona sp. Mar. Drugs 2012, 10, 2126-2137. [CrossRef] [PubMed]

121. Einarsdottir, E.; Magnusdottir, M.; Astarita, G.; Köck, M.; Ögmundsdottir, H.; Thorsteinsdottir, M.; Rapp, H.; Omarsdottir, S.; Paglia, G. Metabolic profiling as a Screening tool for cytotoxic compounds: Identification of 3-alkyl pyridine alkaloids from sponges collected at a shallow water hydrothermal vent Site North of Iceland. Mar. Drugs 2017, 15, 52. [CrossRef]

122. Laville, R.; Genta-Jouve, G.; Urda, C.; Fernández, R.; Thomas, O.; Reyes, F.; Amade, P. Njaoaminiums A, B, and C: Cyclic 3-alkylpyridinium salts from the marine sponge Reniera sp. Molecules 2009, 14, 4716-4724. [CrossRef]

123. Williams, D.E.; Lassota, P.; Andersen, R.J. Motuporamines A-C, cytotoxic alkaloids isolated from the marine sponge Xestospongia exigua (Kirkpatrick). J. Org. Chem. 1998, 63, 4838-4841. [CrossRef]

124. Williams, D.E.; Craig, K.S.; Patrick, B.; McHardy, L.M.; van Soest, R.; Roberge, M.; Andersen, R.J. Motuporamines, anti-invasion and anti-angiogenic alkaloids from the marine sponge Xestospongia exigua (Kirkpatrick): Isolation, structure elucidation, analogue synthesis, and conformational analysis. J. Org. Chem. 2002, 67, 245-258. [CrossRef]

125. Andersen, R.J.; Van Soest, R.W.; Kong, F. 3-Alkylpiperidine alkaloids isolated from marine sponges in the order haplosclerida. In Alkaloids: Chemical and Biological Perspectives, 1st ed.; Pelletier, S.W., Ed.; Pergamon Press: Oxford, UK, 1996; Volume 10, pp. 301-355.

126. Baldwin, J.; Whitehead, R. On the biosynthesis of manzamines. Tetrahedron Lett. 1992, 33, $2059-2062$. [CrossRef]

127. Dorosti, Z.; Yousefi, M.; Sharafi, S.M.; Darani, H.Y. Mutual action of anticancer and antiparasitic drugs: Are there any shared targets? Future Oncol. 2014, 10, 2529-2539. [CrossRef]

128. Gil, L.; Gateau-Olesker, A.; Marazano, C.; Das, B.C. 3-Alkyl 1,6-dihydropyridines from 3-alkyl 5,6-dihydro-pyridinium salts. Implications in the biosynthesis of some macrocyclic marine alkaloids. Tetrahedron Lett. 1995, 36, 707-710. [CrossRef]

129. Jakubowicz, K.; Abdeljelil, K.B.; Herdemann, M.; Martin, M.T.; Gateau-Olesker, A.; Mourabit, A.A.; Marazano, C.; Das, B.C. Reactions of aminopentadienal derivatives with 5,6-dihydropyridinium salts as an approach to manzamine alkaloids based upon biogenetic considerations. J. Org. Chem. 1999, 64, 7381-7387. [CrossRef]

130. Kubota, T.; Kurimoto, S.; Kobayashi, J. The manzamine alkaloids. In The Alkaloids: Chemistry and Biology, 1st ed.; Knölker, H.-J., Ed.; Academic Press: Cambridge, MA, USA, 2020; Volume 84, pp. 1-124. 